\title{
A long Saharan dust event over the western Mediterranean: Lidar, Sun photometer observations, and regional dust modeling
}

\author{
C. Pérez, ${ }^{1}$ S. Nickovic, ${ }^{2,3}$ J. M. Baldasano, ${ }^{1}$ M. Sicard, ${ }^{4}$ F. Rocadenbosch, ${ }^{4}$ \\ and V. E. Cachorro ${ }^{5}$ \\ Received 10 August 2005; revised 26 January 2006; accepted 4 May 2006; published 12 August 2006.
}

[1] A long Saharan dust event affected the western Mediterranean in the period 1228 June 2002. Dust was present mainly between 1- and 5-km height affecting most parts of the Iberian Peninsula and reaching western/central Europe. Intensive backscatter lidar observations over Barcelona (Spain) and Sun photometer data from two stations (El Arenosillo, Spain, and Avignon, France) are used to evaluate different configurations the Dust Regional Atmospheric Modeling (DREAM) system. DREAM currently operates dust forecasts over the Mediterranean region (http://www.bsc.es/projects/earthscience/ DREAM/) considering four particle size bins while only the first two are relevant for long-range transport analysis since their life time is larger than 12 hours. A more detailed bin method is implemented, and two different dust distributions at sources are compared to the operational version. Evaluations are performed at two wavelengths (532 and $1064 \mathrm{~nm}$ ). The dust horizontal and vertical structure simulated by DREAM shows very good qualitative agreement when compared to SeaWIFS satellite images and lidar height-time displays over Barcelona. When evaluating the modeled aerosol optical depth (AOD) against Sun photometer data, significant improvements are achieved with the use of the new detailed bin method. In general, the model underpredicts the AOD for increasing Angström exponents because of the influence of anthropogenic pollution in the boundary layer. In fact, the modeled AOD is highly anticorrelated with the observed Ångström exponents. Avignon shows higher influence of small anthropogenic aerosols which explains the better results of the model at the wavelength of $1064 \mathrm{~nm}$ over this location. The uncertainties of backscatter lidar inversions $(20-30 \%)$ are in the same order of magnitude as the differences between the model experiments. Better model results are obtained when comparing to lidar because most of the anthropogenic effect is removed.

Citation: Pérez, C., S. Nickovic, J. M. Baldasano, M. Sicard, F. Rocadenbosch, and V. E. Cachorro (2006), A long Saharan dust event over the western Mediterranean: Lidar, Sun photometer observations, and regional dust modeling, J. Geophys. Res., 111, D15214, doi:10.1029/2005JD006579.

\section{Introduction}

[2] A large amount of mineral dust is mobilized over arid regions and injected into the atmosphere under favorable weather conditions. Deserts are the main sources of soilderived aerosol. Estimates of the amount of dust exported annually from northern Africa (Sahara-Sahel region) are still

\footnotetext{
${ }^{\mathrm{I}}$ Earth Sciences Division, Barcelona Supercomputing Center, Barcelona, Spain.

${ }^{2}$ Euro-Mediterranean Center on Insular Coastal Dynamics, University of Malta, Foundation for International Studies, Valletta, Malta.

${ }^{3}$ Now at Atmospheric Research and Environment Program, Environment Division, World Meteorological Organization, Geneva, Switzerland.

${ }^{4}$ Remote Sensing Laboratory, Group of Electromagnetic Engineering and Photonics, Department of Signal Theory and Communications, Universitat Politècnica da Catalunya, Barcelona, Spain.

${ }^{5}$ Atmospheric Optic Group, Universidad de Valladolid, Valladolid, Spain.
}

Copyright 2006 by the American Geophysical Union. 0148-0227/06/2005JD006579\$09.00 not reliable, and range from 260 to $1500 \times 10^{6}$ tons/year [Schütz et al., 1981; N'Tchayi et al., 1997; Tegen and Fung, 1994]. Once in the atmosphere, dust particles interact with solar and thermal radiation, modulating the Earth radiation balance, and cause large uncertainties in assessing climate forcing by atmospheric aerosols. It is also accepted that absorption and reflection by dust may substantially affect the thermal structure and thus the atmospheric circulation at synoptic timescales. Furthermore, dust interacts with clouds [Yin et al., 2002], after absorbing hygroscopic material [Levin et al., 1996], and affects photololysis rates and ozone chemistry by modifying the UV radiation [e.g., Dentener et al., 1996; Zerefos et al., 2002; Balis et al., 2002]. Saharan dust deposition influences the biochemical cycles of both oceanic [Kremling and Streau, 1993] and terrestrial ecosystems [Reichholf, 1986], and interfere with the monitoring of the incidence of anthropogenic emissions on ambient air $\mathrm{PM}_{10}$ levels over southern Europe [Rodriguez et al., 2001]. In the regions neighboring deserts, mineral dust also repre- 
sents a risk for human health [Yin et al., 2005] and air transport activities.

[3] Because of its proximity to North Africa, the Mediterranean area is strongly affected by the presence of desert dust. Unsatisfactory description of the dust cycle is mainly due to the lack of enough dense and regular measurements, but also to the incomplete understanding of dust processes such as production, transport, physical and chemical evolution, optical properties and removal of dust [Sokolik et al., 2001]. In the last years, a number of studies have focused on understanding different phases of the dust cycle over the Mediterranean and Europe based on satellite imaging [e.g., Moulin et al., 1997, 1998; Alpert and Ganor, 2001; Israelevich et al., 2002], in situ measurements of depositions, concentrations and optical depths [e.g., Bergametti et al., 1989; Guerzoni et al., 1992; Loye-Pilot and Martin, 1996; Avila et al., 1997; Rodríguez et al., 2001; Israelevich et al., 2003], and lidar observations [e.g., Hamonou et al., 1999; Di Sarra et al., 2001; Gobbi et al., 2000; Ansmann et al., 2003; Müller et al., 2003; Balis et al., 2004; Papayannis et al., 2005].

[4] Also, several regional models for simulation and prediction of the atmospheric dust cycle have been developed in the past decade [e.g., Nickovic and Dobricic, 1996; Kallos et al., 1997; Özsoy et al., 2001; Nickovic et al., 2001]. These models are essential to complement dustrelated observations, understand the dust cycle and predict the impact of dust on surface level PM concentrations over Europe. In this context, the Dust Regional Atmospheric Model (DREAM) [Nickovic et al., 2001] has reached a level of delivering reliable operational dust forecasts (http:// www.bsc.es/projects/earthscience/DREAM/) capable to predict all the major dust events over the region. However, the current operational version has still large development possibilities. DREAM operates dust forecasts considering four dust size transport bins while only the first two are relevant for long-range transport since their life time is larger than 12 hours. Ongoing developments on dust-cloud microphysics and dust-radiation interactions [Nickovic et al., 2004; Pérez et al., 2006] from which climate and weather prediction models can benefit, require better understanding and specification of dust source processes, size distributions and optical properties.

[5] In order to implement new model versions for operational applications there is a need for extensive checking and validation with observations. Nowadays, the monitoring systems include conventional surface observations operating at urban and rural areas, and remote sensing systems. Deposition or surface concentration data involve close-toground characteristics of the dust process. However, longrange transport of desert dust mainly takes place in the free troposphere [Prospero et al., 1981; Mattis et al., 2002; Ansmann et al., 2003]. Thus Sun photometers delivering spectrally resolved column-integrated data in combination with aerosol lidar devices providing information on the vertical structure seem the most appropriate tools for model evaluation.

[6] In this study, a more detailed bin method and two different dust source distributions are implemented into DREAM and compared to the current operational configuration. A long event (12-28 June 2002) of Saharan dust transport toward the western Mediterranean is selected for the analysis. The methodology is developed in section 2. In section 3.1, synoptic charts and satellite images are used to explain the weather conditions and airflow patterns which drove dust-rich air masses toward southwestern Europe for 17 consecutive days. Detailed qualitative evaluation of the evolution of the modeled dust horizontal and vertical structure is performed. In sections 3.3 and 3.4, Sun photometer data from two stations at El Arenosillo (Spain) and Avignon (France), and intensive backscatter lidar observations over Barcelona (Spain) are used to quantitatively evaluate the dust model experiments. Detailed discussion is also undertaken on the relationship between modeled dust concentration, modeled particle size distributions and modeled optical depth. A previous characterization and discussion of the optical and microphysical properties of the Saharan dust plume is done in section 3.2 in order to properly evaluate and analyze the differences between the modeling experiments. This is a crucial task since Sun photometer observations involve considerable uncertainties due to the nonsphericity of dust particles and the influence of boundary layer aerosols.

\section{Methods}

\subsection{Measurements}

\subsubsection{EARLINET Barcelona Lidar}

[7] The aerosol backscatter lidar system of the Technical University of Catalonia (Barcelona $41^{\circ} 23^{\prime} \mathrm{N}, 2^{\circ} 07^{\prime} \mathrm{E}, 115 \mathrm{~m}$ asl, Spain) is based on a Nd:YAG laser emitting at 1064 or $532 \mathrm{~nm}$ [Rocadenbosch et al., 2000]. The range resolution is $7.5 \mathrm{~m}$ and, depending on the integration time, useful signal can be obtained from $300 \mathrm{~m}$ up to $15000 \mathrm{~m}$ asl. The Barcelona lidar station is one of the 20 stations forming part of the European Aerosol Research Lidar Network (EARLINET) [Bösenberg et al., 2003]. In order to ensure high-quality data, EARLINET lidars were intercalibrated in several campaigns [Böckmann et al., 2004; Matthias et al., 2004]. Lidar measurements at one wavelength can provide aerosol backscatter and extinction profiles using inversion techniques [Klett, 1981; Fernald, 1984]. These techniques are generally subject to uncertainties because the lidar system equation contains two unknown parameters for only one single equation: the aerosol extinction and backscatter coefficients. In order to solve the equation for the aerosol backscatter coefficient, a relationship between the two quantities, an extinction-to-backscatter ratio (hereinafter referred to as lidar ratio) has to be assumed. This value introduces errors that may exceed 20\% [Sasano et al., 1985] especially in cases with high aerosol optical depth. At Barcelona, the most powerful method that was found for single wavelength lidar signal inversion, is a combination of the usual Klett [Klett, 1981] backward method applied with the comments from Fernald [1984] and Sasano and Nakane [1984] in an iterative process. In this study, columnintegrated lidar ratios derived from AERONET data (section 2.1.2; equation (1)) are examined and discussed together with previous studies over the area in order to estimate an appropriate value for dust profiles.

\subsubsection{AERONET Sun Photometers}

[8] Data from two stations of the Aerosol Robotic Network (AERONET [Holben et al., 1998]) are used: El Arenosillo ( $37^{\circ} 06^{\prime} \mathrm{W} 06^{\circ} 43^{\prime}$ ) and Avignon (N $43^{\circ} 55^{\prime}$ 
$\mathrm{E} 04^{\circ} 52^{\prime}$ ), hereinafter referred to as $\mathrm{AR}$ and $\mathrm{AV}$, respectively. AERONET systems are globally distributed Sun and sky-scanning ground-based automated radiometers providing column-averaged aerosol optical and microphysical properties. At both stations, spectral observations of Sun and radiance are made at nominal wavelengths of 440, 670, 870 , and $1020 \mathrm{~nm}$. Aerosol optical depth (AOD) is derived from Sun measurements and the addition of aureole radiances together with an AERONET inversion algorithm [Dubovik and King, 2000] allows to retrieve the microphysical and radiative aerosol parameters: particle size distributions, refractive index, the single-scattering albedo and asymmetry parameter. A good and short description about this type of instrument and its derived aerosol quantities relevant to lidar and Sun photometer comparison is given by Müller et al. [2003]. Because of the use of both type of data, lidar and Sun photometer in this study, the AOD and the optical properties are interpolated to the lidar wavelengths of 532 and $1064 \mathrm{~nm}$. The accuracy of the AOD measurements is estimated to be of the order of \pm 0.02 regarding the level 2 data used at AR and of the order of \pm 0.03 regarding the level 1.5 data used at AV. The Ångström exponent (AE) which provides the spectral dependence of the AOD is derived from the ratio between the AOD at 532 and $1064 \mathrm{~nm}$. A column-integrated lidar ratio $S(\lambda)$ can be estimated from Sun photometer data, according to:

$$
S(\lambda)=\frac{4 \pi}{w(\lambda) P\left(\lambda, 180^{\circ}\right)}
$$

where $w(\lambda)$ is the single-scattering albedo and $\mathrm{P}\left(\lambda, 180^{\circ}\right)$ is the particle phase function at $180^{\circ}$.

[9] The nonspherical shape of aerosols increases the lidar ratio in comparison to similar spherical scatterers [Mishchenko et al., 1997; Mattis et al., 2002]. In fact, there is sufficient theoretical and experimental evidence that nonsphericity of desert dust can result in significantly different scattering properties than those predicted by Mie theory [Mishchenko et al., 2000; Dubovik et al., 2002a; Müller et al., 2003]. Numerical tests have shown that dust nonsphericity may cause two kinds of retrieval artifacts: (1) a high concentration of very small particles with radii less than $0.1 \mu \mathrm{m}$, and (2) an unrealistically strong decrease of the real part of the refractive index with decreasing wavelength. These artifacts can be widely eliminated if dust particles are assumed to be randomly oriented spheroids [Dubovik et al., 2002b]. This approach is used in the present study.

[10] Errors of the phase functions at $180^{\circ}$ can reach $50 \%$ if the wrong particle shape is considered [Müller et al., 2003]. Dubovik et al. [2000, 2002b] showed that the complex refractive index is accurately determined for AOD $\geq 0.5$ at $440 \mathrm{~nm}$ under solar zenith angles $>50^{\circ}$. The accuracy for the imaginary part drops by a factor of 2 for AOD's $\leq 0.2$ at $440 \mathrm{~nm}$. Similar to the particle extinction coefficient, the single-scattering albedo is sensitive to the cross section of the particles and thus only slightly affected by particle shape [Mishchenko et al., 1997]. Extensive sensitivity studies that describe the accuracy of the retrieved microphysical properties are given by Dubovik et al. [2000]. Taking into account that we selected measurements with AOD $>0.3$ and solar zenith angle $>45^{\circ}$, we estimate that the accuracy of the single-scattering albedo is in the order of $0.03-0.04$.

\subsection{Dust Regional Atmospheric Modeling (DREAM) System}

\subsubsection{General Aspects}

[11] DREAM (see Nickovic et al. [2001] for details) is a regional model designed to simulate and/or predict the atmospheric cycle of mineral dust aerosol. It solves the Euler-type partial differential nonlinear equation for dust mass continuity. DREAM is fully inserted as one of the governing equations in the atmospheric NCEP/Eta atmospheric model. The concentration equation simulates all major processes of the atmospheric dust cycle. During the model integration, calculation of the surface dust injection fluxes is made over the model points declared as deserts. Once injected into the air, dust aerosol is driven by the atmospheric model variables: by turbulent parameters in the early stage of the process when dust is lifted from the ground to the upper levels; by model winds in the later phases of the process when dust travels away from the sources; finally, by thermodynamic processes and rainfall of the atmospheric model and land cover features which provide wet and dry deposition of dust over the Earth surface.

[12] One of the key components of the dust model is the treatment of sourcing terms in the concentration continuity equation. Failure to adequately simulate/predict the production phase of the dust cycle leads to wrong representation of all other dust processes in the model. Therefore special attention is made to properly parameterize dust production phase. Wind erosion of the soil in DREAM parameterization scheme is controlled mainly by the following factors: type of soil, type of vegetation cover, soil moisture content, and surface atmospheric turbulence. The major input data used to distinct the dust productive soils from the others is a global data set on land cover. In the model, grid points acting as desert dust sources are specified using arid and semiarid categories of the global USGS $1-\mathrm{km}$ vegetation data set. Another data participating in dust production calculations is the FAO 4-km global soil texture data set from which particle size parameters are evaluated. In DREAM, concentration is used as a surface condition. The released surface concentration of mobilized particles and the corresponding surface vertical flux depends on the structure and state of the soil and the turbulent regime of the lower atmosphere. The vertical flux of dust is also a function of friction velocity and soil moisture.

\subsubsection{New Developments and Experimental Design}

[13] We selected a dust event that affected the western Mediterranean during the period 12-28 June 2002 and we performed three different simulations. M4 refers to the current operational configuration of the model, where for each texture class fraction four particle size classes (clay, small silt, large silt and sand) are estimated with particle size radii of $0.73,6.1,18$ and $38 \mu \mathrm{m}$, respectively. For longrange transport, only the first two dust classes are relevant for the analysis since their life time is larger than about 12 hours. In this case one may assume a constant specific extinction cross section $\left(\sigma_{\lambda}^{*}\right)$, which is the ratio of the extinction coefficient to the aerosol mass concentration, to 
Table 1. Transport Bins and Sub-Bin Distribution Parameters ${ }^{\mathrm{a}}$

\begin{tabular}{clccccc}
\hline Bin & $\begin{array}{c}\mathrm{r}_{\min }-\mathrm{r}_{\max }, \\
\mu \mathrm{m}\end{array}$ & $\begin{array}{c}\mathrm{r}_{\text {eff }}, \\
\mu \mathrm{m}\end{array}$ & \multicolumn{1}{c}{$\mathrm{r}_{\mathrm{n}}$} & $\sigma_{\mathrm{g}}$ & $\begin{array}{c}\mathrm{Q}_{\mathrm{e}} \\
532 \mathrm{~nm}\end{array}$ & $\begin{array}{c}\mathrm{Q}_{\mathrm{e}} \\
1064 \mathrm{~nm}\end{array}$ \\
\hline 1 & $0.1-0.18$ & 0.15 & 0.2986 & 2 & 1.373 & 0.217 \\
2 & $0.18-0.3$ & 0.25 & 0.2986 & 2 & 3.303 & 1.043 \\
3 & $0.3-0.6$ & 0.45 & 0.2986 & 2 & 3.245 & 3.300 \\
4 & $0.6-1$ & 0.78 & 0.2986 & 2 & 2.413 & 3.509 \\
5 & $1-1.8$ & 1.3 & 0.2986 & 2 & 2.262 & 2.293 \\
6 & $1.8-3$ & 2.2 & 0.2986 & 2 & 2.260 & 2.282 \\
7 & $3-6$ & 3.8 & 0.2986 & 2 & 2.162 & 2.217 \\
8 & $6-10$ & 7.1 & 0.2986 & 2 & 2.108 & 2.164 \\
\hline
\end{tabular}

${ }^{\mathrm{a}}$ From left to right, the columns are bin number, minimum and maximum radius of each size bin, effective radius of each bin, number median radius of the distribution, geometric standard deviation, extinction efficiency at 532 and $1064 \mathrm{~nm}$

obtain the modeled AOD $[\tau(\lambda)]$ and extinction coefficient $[\alpha(\lambda)]$

$$
\begin{aligned}
& \tau(\lambda)=\sigma_{\lambda}^{*} M \\
& \alpha(\lambda)=\sigma_{\lambda}^{*} C
\end{aligned}
$$

where $\mathrm{M}$ is the column mass loading and $\mathrm{C}$ is the mass concentration from the model.

[14] As introduced in section 1 particle size distribution is one of the key modeling factors in order to correctly incorporate dust-radiation and dust-cloud interactions into regional dust models. Thus this study also evaluates a more detailed bin method in which the two first categories (clay and small silt) are divided into 8 size bins between 0.1 and $10 \mu \mathrm{m}$. In this interval, the aerosol effects on solar radiation are most significant. The bin intervals are the same as used by Tegen and Lacis [1996] (Table 1). In this case, $\tau(\lambda)$ and the $\alpha(\lambda)$ are related to column mass loading and mass concentration, respectively, by:

$$
\begin{aligned}
& \tau(\lambda)=\sum_{1}^{8} \tau_{k}(\lambda)=\sum_{1}^{8} \frac{3}{4 \rho_{k} r_{k}} M_{k} Q_{\text {ext }}(\lambda)_{k} \\
& \alpha(\lambda)=\sum_{1}^{8} \alpha_{k}(\lambda)=\sum_{1}^{8} \frac{3}{4 \rho_{k} r_{k}} C_{k} Q_{\text {ext }}(\lambda)_{k}
\end{aligned}
$$

where for each size bin $\mathrm{k}: \tau_{\mathrm{k}}(\lambda)$ is the AOD, $\alpha_{\mathrm{k}}(\lambda)$ the extinction coefficient, $\rho_{\mathrm{k}}$ is the particle mass density, $r_{\mathrm{k}}$ is the effective radius, $M_{k}$ is the column mass loading, $C_{k}$ is the concentration and $\mathrm{Q}_{\text {ext }}(\lambda)_{\mathrm{k}}$ is the extinction efficiency factor which was calculated using Mie scattering theory. Within each transport bin, dust is assumed to have timeinvariant, sub-bin lognormal distribution [Zender et al., 2003] employing the transport mode with mass median diameter of $2.524 \mu \mathrm{m}$ [Shettle, 1984] and geometric standard deviation 2.0 [Schulz et al., 1998]. The analytic sub-bin distribution allows accurate prescription of physical and optical properties known to vary across the bin width. Table 1 indicates the calculated extinction efficiency factor for 532 and $1064 \mathrm{~nm}$.
[15] Because the specification of dust size distribution over the sources is crucial, two different assumptions of source distribution derived from D'Almeida [1987] and Gomes et al. [1990] (Figure 1) are implemented and evaluated (hereinafter referred to as D8 and G8, respectively).

[16] Since there are not yet satisfactory three-dimensional dust concentration observations to be assimilated, the initial state of dust concentration in the model is defined by the 24-hour forecast from the previous day model run. Only in the "cold start" of the model, concentration is set to zero. The cold start of the model was initiated on 8 June 2002. The resolution is set to $50 \mathrm{~km}$ in the horizontal and to 24 layers extending up to approximately $15 \mathrm{~km}$ in the vertical. The domain of simulation covers northern Africa, the Mediterranean sea and southern Europe.

\section{Results and Discussion}

\subsection{Horizontal and Vertical Structure of the Saharan Dust Plume}

[17] Synoptic charts of the geopotential height at $700 \mathrm{hPa}$ and MSL pressure (Figure 2), SeaWIFS satellite images and dust loading maps from the M4 model experiment (Figure 3) depict the evolution of the Saharan dust plume over the study area. Sequences of 3 main meteorological patterns ((1) high pressure over the western Mediterranean, (2) high pressure over northwestern Africa and (3) low pressure over southwestern Portugal) explain how the Saharan dust plume transported toward western Europe remained over the area for more than 2 weeks. From 11 June a westerly wave formed in the upper levels with a N-S trough axis over the Atlantic ocean in the southwest of Portugal and a ridge axis over the Iberian Peninsula (IP). A high-pressure center was present over North Africa. This situation induced SW flows over North Africa and the southern IP. Over the next 48 hours the wave amplitude intensified inducing S-SW flows over Morocco and the southern IP (Figure 2a).

[18] A height-time display of the $1064 \mathrm{~nm}$ range-corrected lidar signal on 13 and 14 June is shown in Figure 4a. This profile was already analyzed and discussed by Pérez et al. [2004]. On 13 June stratified aerosol layers were present

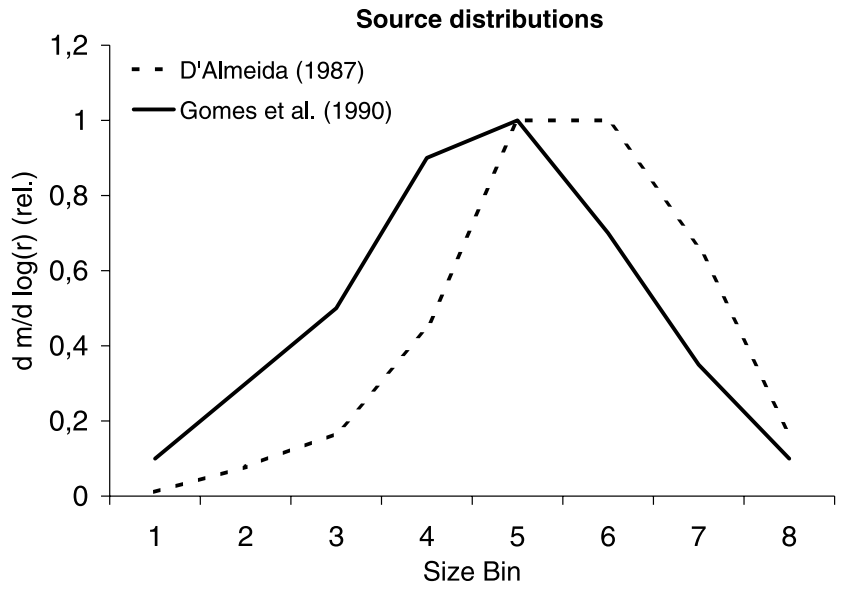

Figure 1. Parameterizations of mass size distribution of the model at sources (in relative units): D8 [D'Almeida, 1987] and G8 [Gomes et al., 1990]. 

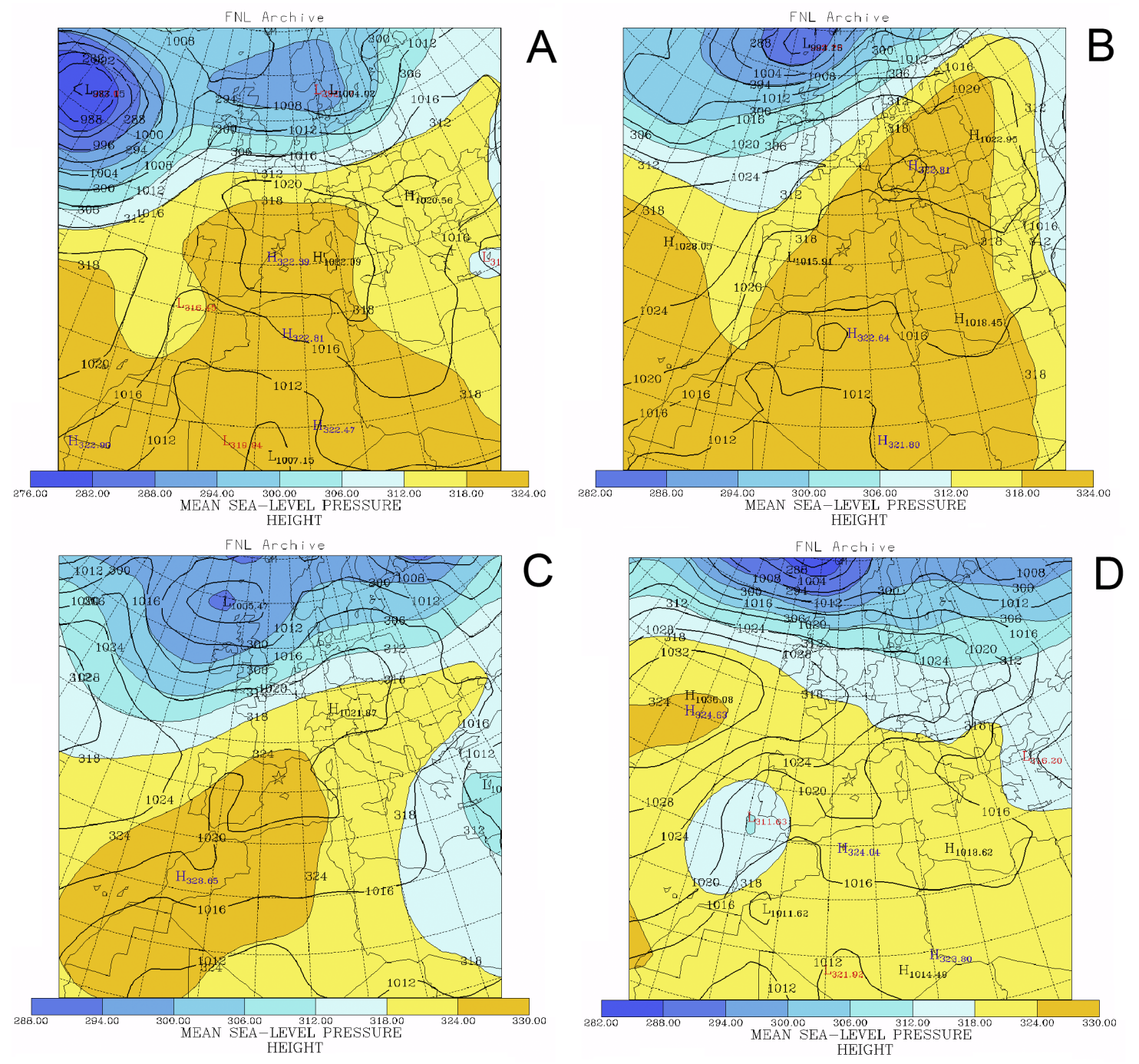

Figure 2. Mean sea level pressure (contour lines) and geopotential height (color-shaded) at $700 \mathrm{hPa}$ on (a) 13 June, (b) 19 June, (c) 22 June, and (d) 25 June.

up to $3000-4000 \mathrm{~m}$. Synoptic back trajectory and radiosounding analysis strongly suggested the local/regional origin of the observed layers. On 14 June, the lidar diurnal cycle shows two differentiated aerosol structures: plumelike structures from 3500 to $5500 \mathrm{~m}$ (in the afternoon) with traces of aerosol up to $7000 \mathrm{~m}$ and a more stratified structure below $3000 \mathrm{~m}$ throughout the day. Back trajectories (not shown) and model's dust loading map (Figure 3a) and height-time display (Figure 4a) clearly identify the Saharan origin of the upper plume-like structures.

[19] The lidar height time display on 16-17 June is shown in Figure 4b. The core of the dust layer was confined to $1800-2500 \mathrm{~m}$ on 16 June and to $1800-3000 \mathrm{~m}$ on 17 June with dust presence up to $4500 \mathrm{~m}$.

[20] On 18 June, the high-pressure area moved southwestward and again a NW-SE trough axis formed southwest of Portugal which intensified on 19 June (Figure 2b). The Seawifs image (Figure 3b) depicts the Saharan dust plume over the IP, the straight of Gibraltar, the Alborean sea, the eastern IP and the bay of Biscay. The lidar height-time display in Figure 4c outlines the presence of 2 dust layers between 1500 and $5000 \mathrm{~m}$ on 18 June which appeared to be merged into 1 thick layer on the next day.

[21] On 21-23 June the center of the high-pressure area established over Morocco inducing SW flows over the IP and the progressive translation toward the east of the axis of the dust plume (Figures 2c and 3c). Accordingly, the lidar height time display (Figure 4d) indicates the presence of dust between 1500 and $5000 \mathrm{~m}$ on 21 June and the progressive reduction of the depth of the dust layer on 22 June. Low concentrations of dust remained over the western Mediterranean on 23 June affecting the eastern coast of the IP. On 24-27 June a low pressure enclosed circulation developed over southwest Portugal (Figure 2d) transporting more dust to the IP and western Europe (Figure 3d). On June 28 the development of the north African anticyclone induced western flows over the western Mediterranean displacing the dust to the central Mediterranean.

[22] Concerning the qualitative performance of the model, the spatial patterns of the dust plume show very good agreement with the corresponding satellite images (Figure 3). Also, the daily evolution of the dust vertical 

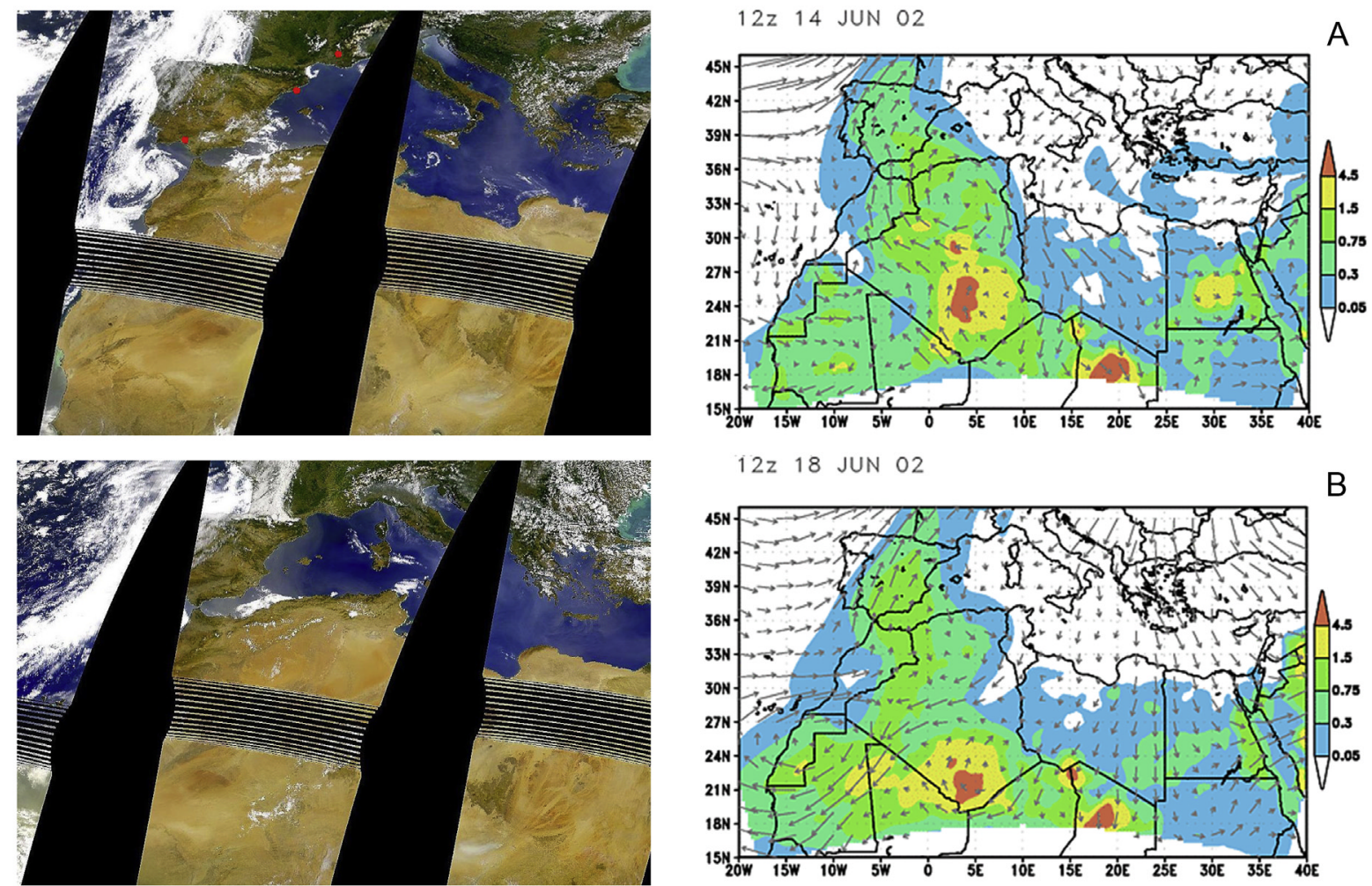

$12 z \quad 18$ JUN 02
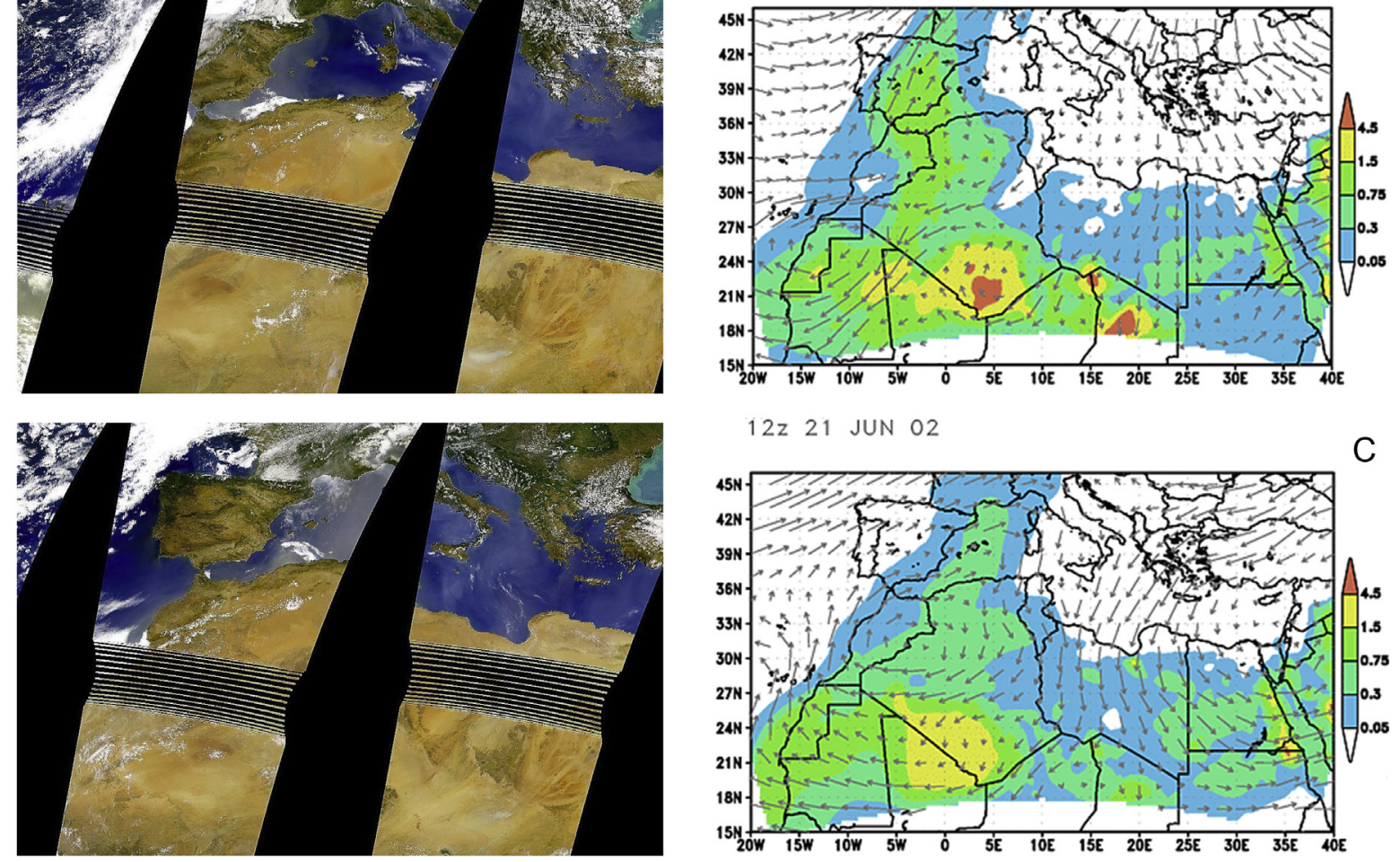

$12 z \quad 21$ JUN 02

C
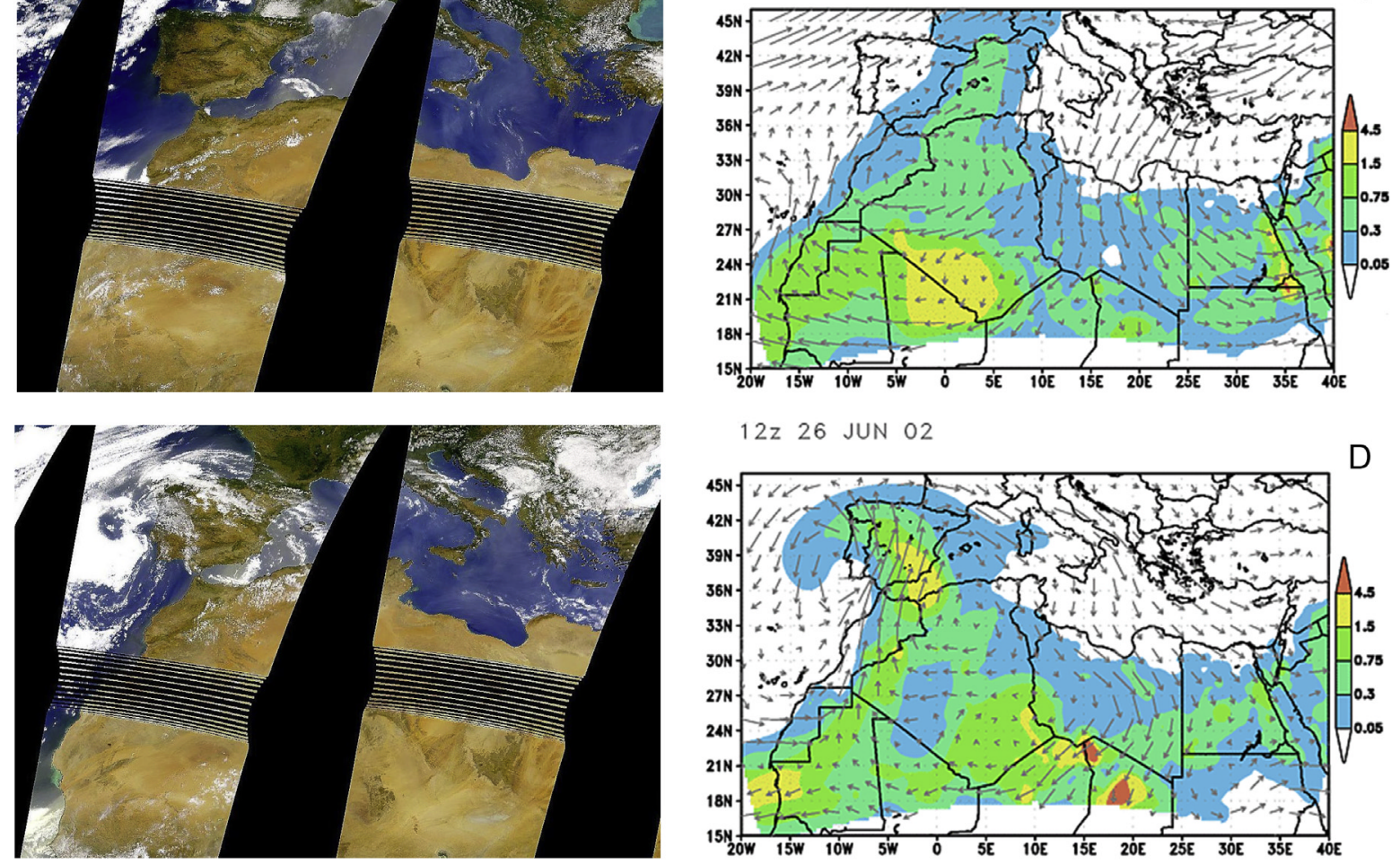

Figure 3. (left) SeaWIFS satellite images and (right) model (M4) dust loading in $\mathrm{gm}^{-3}$ and winds at $3000 \mathrm{~m}$ on (a) 14 June, (b) 18 June, (c) 21 June, and (d) 26 June. The red spots indicate the location of the stations: El Arenosillo (south), Barcelona (center), and Avignon (north). 

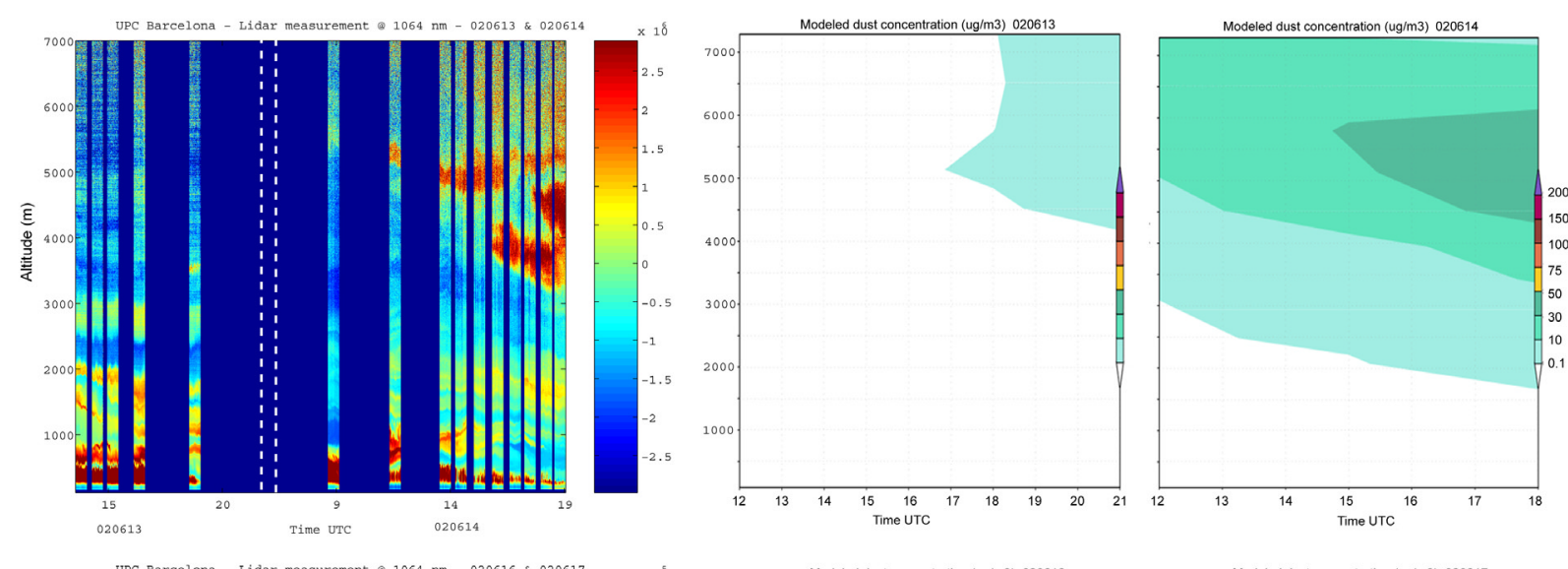

A
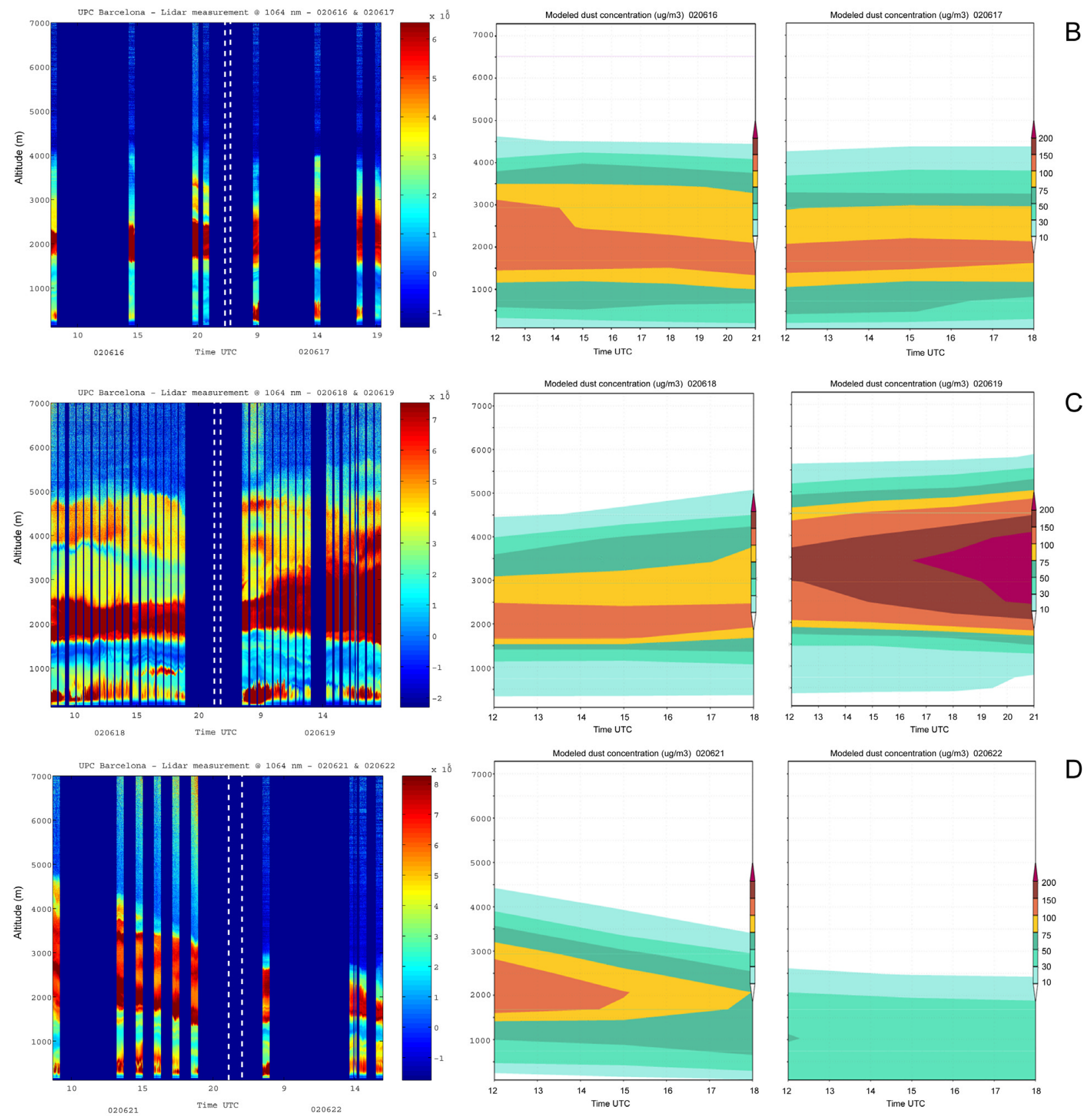

Figure 4. (left) Range corrected lidar signal at $1064 \mathrm{~nm}$ (arbitrary units) (temporal resolution is $60 \mathrm{~s}$ ). Dark blue columns indicate no measurements. (right) Model vertical dust concentration in $\mu \mathrm{gm}^{-3}$ over Barcelona on (a) 13-14 June, (b) 16-17 June, (c) 18-19 June, and (d) 21-22 June. 

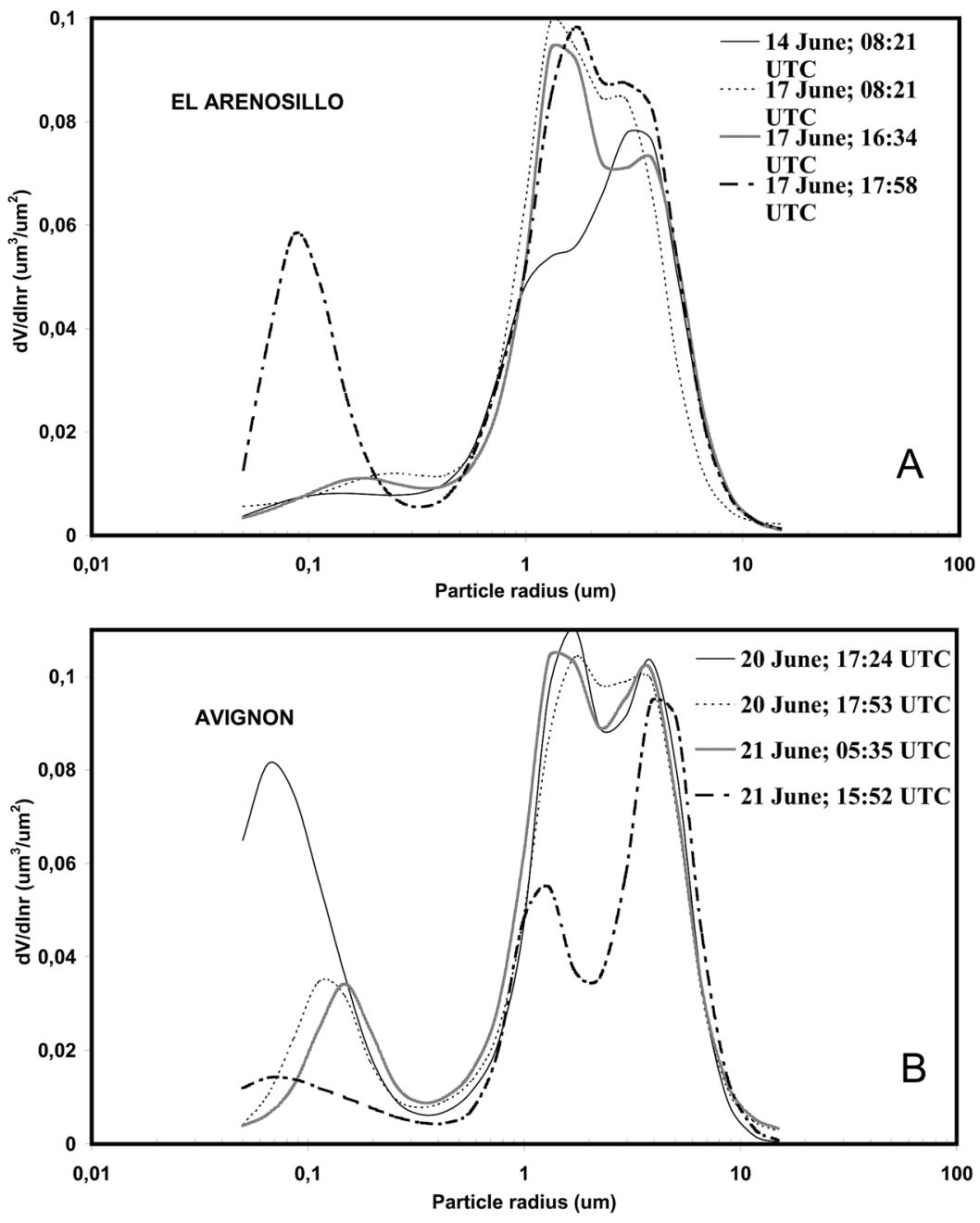

Figure 5. Selected column-averaged particle size distributions retrieved from Sun photometer for the spheroidal particle model at (a) El Arenosillo (AR) and (b) Avignon (AV).

structure observed by the lidar over Barcelona is very well captured by the model (Figure 4).

\subsection{Dust Optical and Microphysical Properties}

[23] A selection of volume particle size distributions from both AERONET stations is depicted in Figure 5. Table 2 presents column-integrated results for number mode radius $\left(r_{n, i}\right)$ and geometric standard deviation $\left(\sigma_{\mathrm{c}}\right.$ and $\left.\sigma_{\mathrm{f}}\right)$ for coarse $(0.6<\mathrm{r}<15 \mu \mathrm{m})$ and fine $(0.05<\mathrm{r}<0.6 \mu \mathrm{m})$ modes, effective radius $\left(\mathrm{r}_{\mathrm{eff}}\right)$, and the following set of interpolated parameters at 532 and $1064 \mathrm{~nm}$ : single-scattering albedo $\mathrm{w}(\lambda)$, real and imaginary part of the complex refractive index $(\mathrm{n}(\lambda), \mathrm{k}(\lambda))$, particle phase function at $180^{\circ} \mathrm{P}(\lambda$, $\left.180^{\circ}\right)$ and lidar ratio $S(\lambda)$ which is calculated according to

Table 2. Microphysical Particle Properties From Sun Photometer Observations at El Arenosillo (AR) and Avignon (AV) Stations

\begin{tabular}{|c|c|c|c|c|c|c|c|c|c|c|c|c|c|c|c|c|}
\hline \multirow[b]{2}{*}{ Day } & \multirow[b]{2}{*}{ Time, UTC } & \multirow[b]{2}{*}{$r_{n, f}, \mu m$} & \multirow[b]{2}{*}{$\sigma_{\mathrm{f}}$} & \multirow[b]{2}{*}{$r_{n, c}, \mu m$} & \multirow[b]{2}{*}{$\sigma_{\mathrm{c}}$} & \multirow[b]{2}{*}{$r_{\text {eff }}, \mu \mathrm{m}$} & \multicolumn{5}{|c|}{$532 \mathrm{~nm}$} & \multicolumn{5}{|c|}{$1064 \mathrm{~nm}$} \\
\hline & & & & & & & $\mathrm{w}$ & $\mathrm{n}$ & $\mathrm{k}$ & $\mathrm{P}_{180^{\circ}}$ & $\mathrm{S}, \mathrm{sr}$ & $\mathrm{w}$ & $\mathrm{n}$ & $\mathrm{k}$ & $\mathrm{P}_{180^{\circ}}$ & $\mathrm{S}, \mathrm{sr}$ \\
\hline \multicolumn{17}{|c|}{ El Arenosillo } \\
\hline 14 & 0821 & 0.04 & 1.95 & 0.56 & 1.97 & 0.75 & 0.84 & 1.59 & 0.011 & 0.28 & 54 & 0.87 & 1.55 & 0.011 & 0.26 & 55 \\
\hline 17 & 0821 & 0.05 & 1.93 & 0.64 & 1.84 & 0.71 & 0.87 & 1.58 & 0.008 & 0.30 & 49 & 0.91 & 1.50 & 0.007 & 0.24 & 56 \\
\hline 17 & 1634 & 0.05 & 1.86 & 0.63 & 1.90 & 0.78 & 0.89 & 1.55 & 0.006 & 0.30 & 47 & 0.92 & 1.50 & 0.005 & 0.27 & 51 \\
\hline 17 & 1758 & 0.05 & 1.65 & 0.66 & 1.88 & 0.32 & 0.93 & 1.37 & 0.003 & 0.24 & 57 & 0.96 & 1.48 & 0.002 & 0.31 & 42 \\
\hline \multicolumn{17}{|c|}{ Avignon } \\
\hline 20 & 1724 & 0.04 & 1.67 & 0.76 & 1.86 & 0.22 & 0.95 & 1.41 & 0.002 & 0.31 & 42 & 0.97 & 1.49 & 0.001 & 0.37 & 35 \\
\hline 20 & 1753 & 0.06 & 1.70 & 0.71 & 1.90 & 0.54 & 0.94 & 1.51 & 0.003 & 0.29 & 46 & 0.96 & 1.51 & 0.003 & 0.35 & 37 \\
\hline 21 & 0535 & 0.07 & 1.68 & 0.62 & 1.93 & 0.63 & 0.93 & 1.51 & 0.004 & 0.26 & 51 & 0.95 & 1.52 & 0.004 & 0.34 & 39 \\
\hline 21 & 1552 & 0.03 & 1.88 & 0.63 & 2.01 & 0.53 & 0.94 & 1.60 & 0.003 & 0.43 & 31 & 0.95 & 1.60 & 0.003 & 0.48 & 28 \\
\hline
\end{tabular}



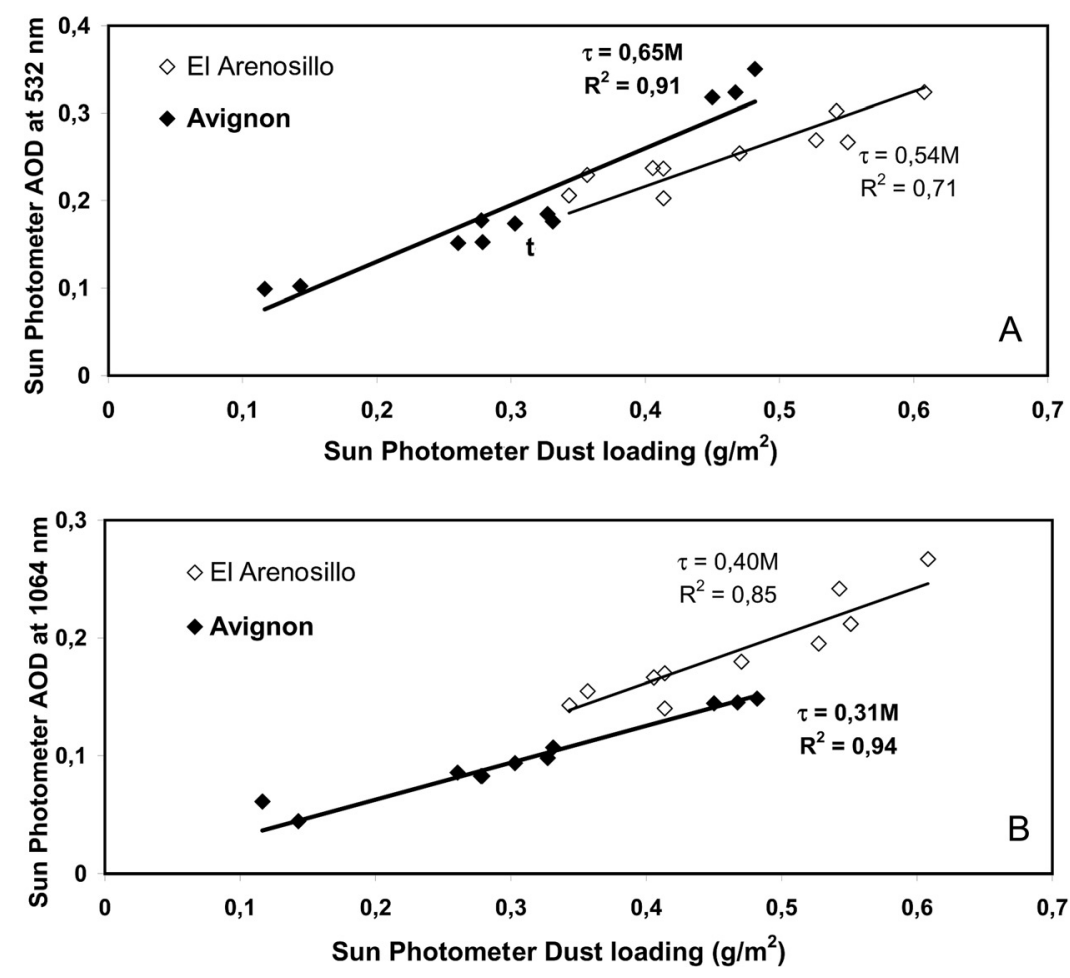

Figure 6. Sun photometer AOD versus dust loading at (a) $532 \mathrm{~nm}$ and (b)1064 nm. Lines indicate the linear regression.

equation (1). We have selected measurements where the solar zenith angle is larger than $45^{\circ}$ and the AOD at $440 \mathrm{~nm}$ larger than 0.3 in order to minimize errors.

[24] As shown by Figure 5, the shape of the particle size distribution shows two modes which represent the mixture of mineral dust and anthropogenic aerosols in the boundary layer. However, the fine mode volume concentration is considerably more important in the case of AV. Indeed, effective radius range $0.71-0.78 \mu \mathrm{m}$ at $\mathrm{AR}$ and $0.53-$ $0.63 \mu \mathrm{m}$ at AV. The pronounced fine mode at AR on 17 June at $1758 \mathrm{UTC}\left(\mathrm{r}_{\text {eff }}=0.32 \mu \mathrm{m}\right)$ and at AV on 20 June $\left(\mathrm{r}_{\text {eff }}=\right.$ $0.22 \mu \mathrm{m})$ are due to inversion errors caused by particle nonsphericity. Although a model of randomly oriented spheroids has been applied (section 2.1.2), both cases show high concentration of very small particles and an unrealistic strong decrease of the real part of the refractive index with decreasing wavelength (from 1.48 to 1.37 at AR and from 1.49 to 1.41 at $\mathrm{AV})$.

[25] The single-scattering albedo ranged $0.84-0.89$ at $532 \mathrm{~nm}$ and $0.87-0.92$ at $1064 \mathrm{~nm}$ over AR, and $0.93-$ 0.94 at $532 \mathrm{~nm}$ and $0.95-0.96$ at $1064 \mathrm{~nm}$ over AV. Because of the dominance of large particles the singlescattering albedo should increase with wavelength. It can be observed that the relative increase is more significant in the case of AR. The retrieved values at AR in the visible wavelengths are consistent with those in the upper end of the range $0.63-0.89$ of some aerosol models [Shettle and Fenn, 1979; Koepke et al., 1997]. However, it shows more absorption than other studies [Fouquart et al., 1987; Kaufman et al., 2001; Dubovik et al., 2002a; Müller et al., 2003]. Results at AV are in better agreement with the latter studies but as discussed in section 3.3, they may be more influenced by European anthropogenic pollution. In this context and for comparison, the single-scattering albedo in AERONET stations influenced by urban-industrial aerosols is in the range $0.93-0.94$ (Creteil (suburb of Paris)) and 0.880.90 (Mexico City), while some aerosol models [e.g., Hess et $a l ., 1998]$ give much higher absorption $[\mathrm{w}(550 \mathrm{~nm})=0.82]$.

[26] The real part of the complex refractive index ranged $1.51-1.60$ at $532 \mathrm{~nm}$ and $1.50-1.60$ at $1064 \mathrm{~nm}$, which is consistent with aerosols models $[\mathrm{k}(550 \mathrm{~nm})=1.53]$ and AERONET retrievals at desert dust influenced locations (1.48-1.56) [Dubovik et al., 2002a]. As discussed for $w(\lambda)$, the imaginary part of the refractive index reflected more absorption at AR $[\mathrm{k}(532 \mathrm{~nm})=0.006-0.011]$ than over AV (0.003-0.004).

\subsection{Modeled Versus Observed Optical Depths}

[27] As already introduced in section 2.1.2, while D8 and G8 yield the modeled AOD through predefined tables of extinction efficiency (equation (4)), in the case of M4, we must estimate an appropriate $\sigma_{\lambda}^{*}$ (equation (2)). Moulin et al. [1997] reviewed several $\sigma_{550}^{*}$ from desert aerosol models. Trimodal background desert dust models representative of transported particles from Shettle [1984] and D'Almeida [1987] derived from measurements in arid regions of Africa delivered $\sigma_{550}^{*}=0.82$ and $0.42 \mathrm{~m}^{2} / \mathrm{g}$, respectively, while the wind-carrying dust model, characteristic of particles near the source gave $\sigma_{550}^{*}=0.12 \mathrm{~m}^{2} / \mathrm{g}$ [D'Almeida, 1987]. Three monomodal models computed by Koepke and Hess [1988] after loess particle size distribution analyses by Schütz [1980], representative of transported dust at different times gave $\sigma_{550}^{*}=0.03 \mathrm{~m}^{2} / \mathrm{g}$ for dust at source, $\sigma_{550}^{*}=0.23 \mathrm{~m}^{2} / \mathrm{g}$ for dust at $2000 \mathrm{~km}$ and $\sigma_{550}^{*}=0.77 \mathrm{~m}^{2} / \mathrm{g}$ for dust at $5000 \mathrm{~km}$. Dulac et 

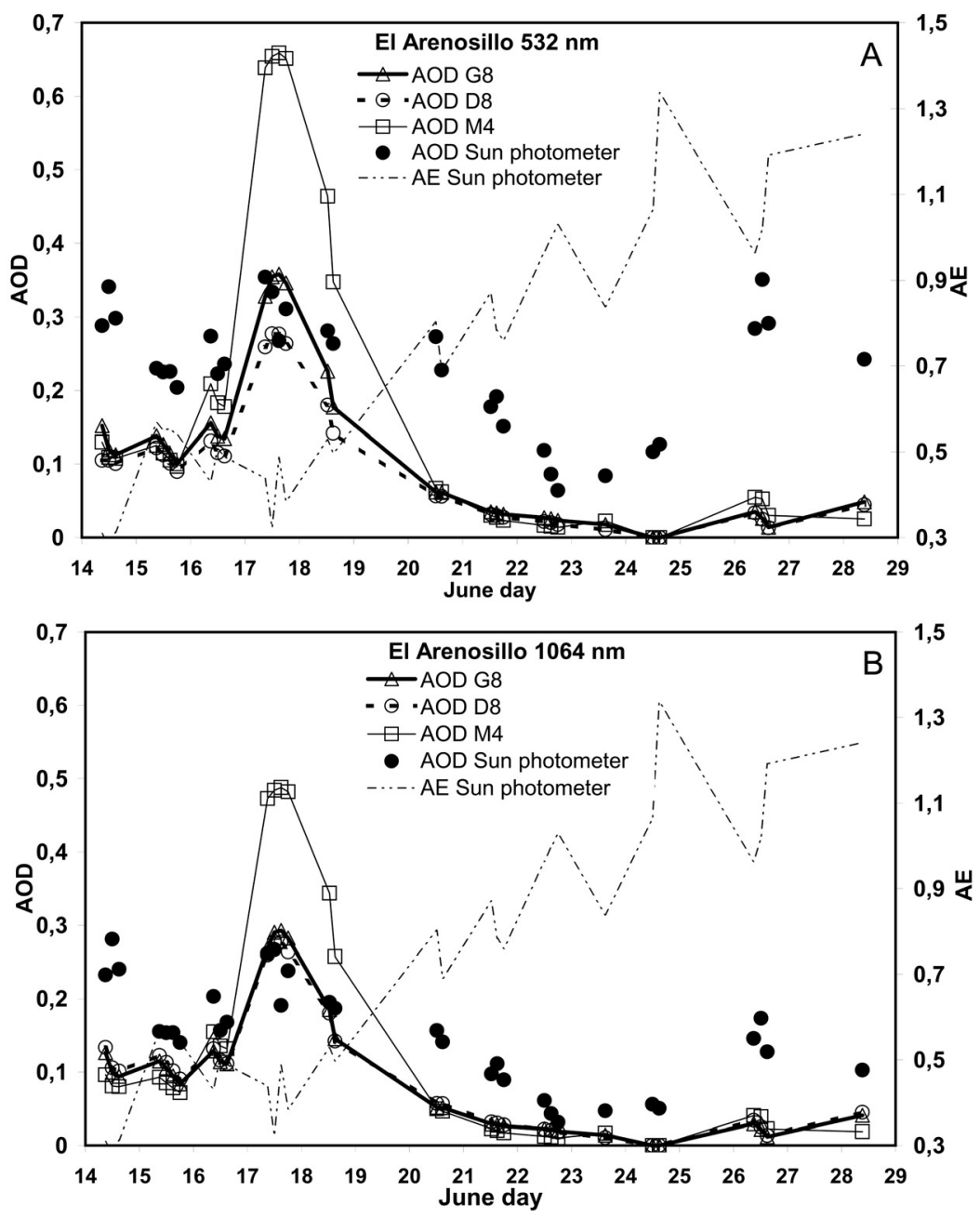

Figure 7. Observed and modeled time series of the interpolated optical depths at (a) $532 \mathrm{~nm}$ and (b) $1064 \mathrm{~nm}$ between 14 and 28 June at El Arenosillo (AR). Sun photometer-derived Ångström exponent is also shown (right axis).

al. [1992a, 1992b] derived $\sigma_{550}^{*}=0.578 \mathrm{~m}^{2} / \mathrm{g}$ and $\sigma_{550}^{*}=$ $0.8 \mathrm{~m}^{2} / \mathrm{g}$ over the western Mediterranean from measurements in Corsica, France. Chin et al. [2002] used $\sigma_{550}^{*}=$ $0.8 \mathrm{~m}^{2} / \mathrm{g}$ in their dust calculations. Maring et al. [2003] derived $0.5 \mathrm{~m}^{2} / \mathrm{g}$ near Africa and inferred $0.6 \mathrm{~m}^{2} / \mathrm{g}$ in Barbados from measurements of Li et al. [1996].

[28] In our study, we estimate $\sigma_{532}^{*}$ and $\sigma_{1064}^{*}$ over the area by linear regression of AOD versus column dust loading (calculated from total volume concentration and assuming a dust density of $2.6 \mathrm{~g} / \mathrm{cm}^{3}$ ) from Sun photometers (Figure 6). It followed that $\sigma_{532}^{*}=0.54 \mathrm{~m}^{2} / \mathrm{g}$ for AR and $0.65 \mathrm{~m}^{2} / \mathrm{g}$ for $\mathrm{AV}$ and $\sigma_{1064}^{*}=0.4 \mathrm{~m}^{2} / \mathrm{g}$ for AR and $0.31 \mathrm{~m}^{2} / \mathrm{g}$ for AV. All of them showed good correlation coefficients with better results for increasing wavelengths. For model validation, we selected results from AR because of the lower influence of anthropogenic particles in this site.

[29] Figures 7 and 8 present the time series of the AOD at 532 and $1064 \mathrm{~nm}$ and $\mathrm{AE}$ for the respective wavelength range derived from Sun photometers, and the AOD from the model experiments (M4, D8 and G8). The measured AOD oscillated between $0.06-0.35(0.04-0.28)$ at $532(1064) \mathrm{nm}$ at AR and between $0.12-0.45(0.03-0.29)$ at $532(1064) \mathrm{nm}$ at AV. Three major peaks are observed on 14 (21), 17 (24) and 26 (27) June at AR (AV).

[30] The relationship between fine and coarse modes can be followed by the AE. Since coarse-mode particles is a feature that differentiates dust from fine-mode anthropogenic aerosols such as urban-industrial particles, an increase (decrease) in the $\mathrm{AE}$ involves an increase (decrease) of the ratio fine/coarse particles and in our case denotes the low (high) influence of the dust plume during the episode. AE values range from 0.3 to 1.3 at $\mathrm{AR}$ and from 0.5 to 2.3 at $\mathrm{AV}$, outlining the higher influence of fine mode particles in the latter location as previously outlined with volume size distributions. For this reason the model shows a general tendency toward AOD underprediction for increasing $\mathrm{AE}$ values partly because Sun photometer data involve columnintegrated values which include the effect boundary layer aerosols. Table 3 outlines the clear anticorrelation between the observed AE and the modeled AOD which is significantly better for G8 and D8 (0.69-0.76) in comparison to M4 (0.56-0.60).

[31] Figure 9 shows the comparisons between modeled and observed AOD differentiating between the measure- 

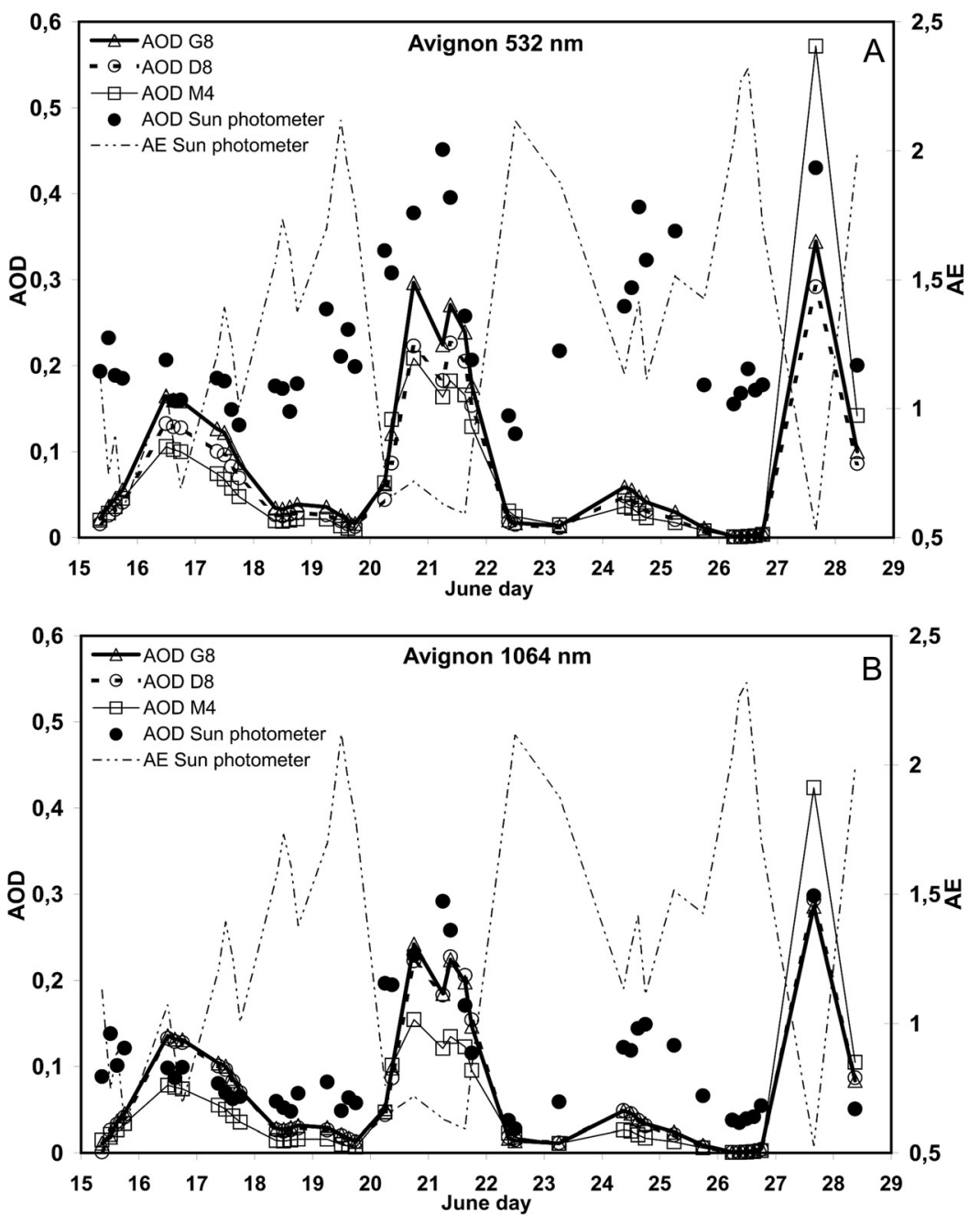

Figure 8. Observed and modeled time series of the interpolated optical depths at (a) $532 \mathrm{~nm}$ and (b) $1064 \mathrm{~nm}$ between 14 and 28 June at Avignon (AV). Sun photometer-derived Ångström exponent is also shown (right axis).

ments related to $\mathrm{AE}$ values larger or smaller than a threshold $\left(\mathrm{AE}_{\mathrm{T}}\right)$. We select $\mathrm{AE}_{\mathrm{T}}=0.6$ for $\mathrm{AR}$ and $\mathrm{AE}_{\mathrm{T}}=0.8$ for $\mathrm{AV}$ given that the latter is more influenced by Euro-Mediterranean anthropogenic aerosols. At AR it is shown that for almost all measurements with $\mathrm{AE}>\mathrm{AE}_{\mathrm{T}}$, the model underpredicts the AOD by more than a factor of 2 .

[32] In general, a decrease in $\mathrm{AE}$ is followed by an increase in the modeled AOD and a much better performance. For example, on 18-19 June at AV the AOD ranged $0.17-0.26$ at $532 \mathrm{~nm}$ and $0.06-0.08$ at $1064 \mathrm{~nm}$. Indeed, model results and satellite images evidence that only traces of dust were present over AV on 18-19 June. Furthermore, back trajectory analysis (not shown) suggest the dominance of Euro-Mediterranean pollutant circulations. Accordingly, the observed AE increased up to 2. On 20-21 June the AOD raised up to $0.25-0.45$ at $532 \mathrm{~nm}$ and $0.17-0.30$ at $1064 \mathrm{~nm}$. The AE strongly decreased to $0.65-0.70$ because of the presence of the dust plume. Although back trajectory analysis (not shown) indicate the combination of EuropeanMediterranean pollutant circulations at low levels and Saharan dust air masses at higher levels we can conclude that the dust plume was dominant. The period 22-26 June at $\mathrm{AV}$ is characterized by a high $\mathrm{AE}$ ( 2.1 on 22 June and 2.3 on 26 June) which is supported by a diminution in the dust load. On 24 June the model shows a slight AOD peak which is anticorrelated with a relative descent of the AE to 1.1 Again, on 27 June the penetration of the core of the dust plume raised the AOD up to 0.43 at $532 \mathrm{~nm}$ and 0.30 at $1064 \mathrm{~nm}$, decreasing the AE to 0.5 which is very well captured by the model.

Table 3. Correlation Coefficient (R) Between the Modeled AOD and the Observed AE for G8, D8 and M4 ${ }^{\mathrm{a}}$

\begin{tabular}{lccc}
\hline & \multicolumn{3}{c}{ R (AE Measured - AOD Modeled) } \\
\cline { 2 - 4 } & G8 & D8 & M4 \\
\hline AR $(1064 \mathrm{~nm})$ & -0.73 & -0.76 & -0.60 \\
AR $(532 \mathrm{~nm})$ & -0.73 & -0.75 & -0.60 \\
AV $(1064 \mathrm{~nm})$ & -0.70 & -0.69 & -0.56 \\
AV $(532 \mathrm{~nm})$ & -0.71 & -0.70 & -0.56 \\
\hline
\end{tabular}

${ }^{\mathrm{a}}$ Results are shown for Avignon (AV) and El Arenosillo (AR) at 532 and $1064 \mathrm{~nm}$. 

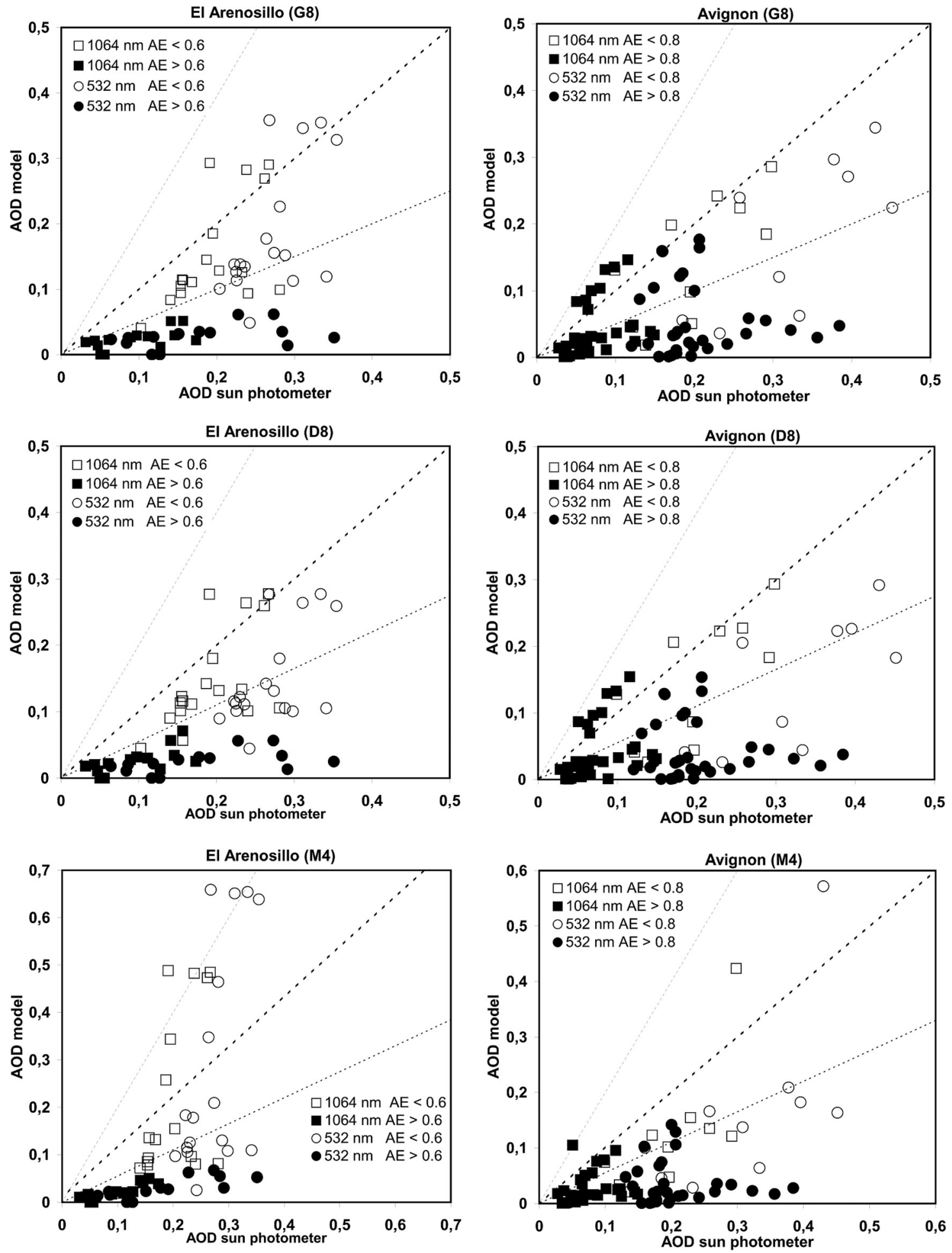

Figure 9. Modeled versus observed AOD for (top) G8, (middle) D8, and (bottom) M4 at El Arenosillo (AR) and Avignon (AV).

[33] M4 shows the worst performance of the three experiments. In general, the model yields much better results at $1064 \mathrm{~nm}$ than at $532 \mathrm{~nm}$, especially at $\mathrm{AV}$, because the former wavelength is less affected by fine anthropogenic aerosols. D8 and G8 deliver very similar AOD values at
$1064 \mathrm{~nm}$. However, the AOD yielded by G8 at $532 \mathrm{~nm}$ is higher. This is related to parameterized distributions at source: G8 shows more relative mass available for uplift in the finer size bins than D8 (Figure 1). Although G8 


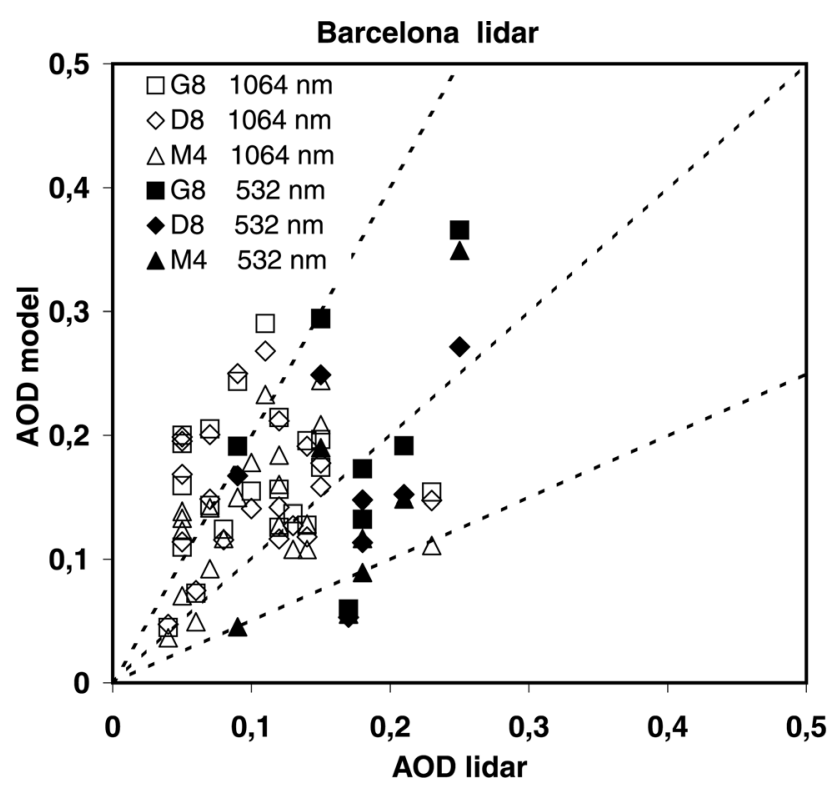

Figure 10. Modeled versus observed AOD for G8, D8, and M4 at Barcelona.

shows a better general behavior at $532 \mathrm{~nm}$ any conclusions can be derived because of the anthropogenic influence.

\subsection{Modeled Versus Observed Vertical Profiles}

[34] Table 1 shows the results of the column-integrated lidar ratio from Sun photometers according to equation (1). It ranges from $47-54 \mathrm{sr}$ at $532 \mathrm{~nm}$ and $51-56 \mathrm{sr}$ at $1064 \mathrm{~nm}$ over AR, and $31-51 \mathrm{sr}$ at $532 \mathrm{~nm}$ and $28-39 \mathrm{sr}$ at $1064 \mathrm{~nm}$ over $\mathrm{AV} . \mathrm{P}\left(\lambda, 180^{\circ}\right)$ and $\mathrm{w}(\lambda)$ are significantly lower at $\mathrm{AR}$, yielding higher lidar ratios. As mentioned before, the lidar ratio increases for nonspherical dust particles in comparison to equivalent spheres. The smaller $\mathrm{P}(1064 \mathrm{~nm}$, $180^{\circ}$ ) at AR also could be partly due to the higher effective radius in comparison to AV. Thus the lidar ratio differences between AR and AV may be explained by the contribution of boundary layer anthropogenic aerosols in the later station.

[35] Mattis et al. [2002] observed large dust lidar ratios at $532 \mathrm{~nm}$ by means of Raman lidar over Leipzig (Germany) after long-range transport. An extended study of this episode by Müller et al. [2003] showed that Sun photometerderived lidar ratios $(35 \pm 18 \mathrm{sr})$ were underestimated in comparison to Raman lidar results (62 $\pm 12 \mathrm{sr}$ ), concluding that these deviations could be improved with the variation of the distribution of aspect ratios in the spheroidal model.

[36] In view of our results and the previous considerations, a constant lidar ratio of $60 \mathrm{sr}$ was used to invert the lidar profiles over Barcelona. In fact, Ansmann et al. [2003] suggests this value as the most appropriate for Saharan dust after long-range transport to western and northern Europe.

[37] Figure 10 presents the comparison between the modeled AOD and the lidar AOD at 532 and $1064 \mathrm{~nm}$. As shown by Figure 3, the PBL height remains below 1-km height during the whole episode, so the calculation of the lidar AOD was done by the integration of the respective extinction coefficients above 1-km height, although mixing between dust and PBL anthropogenic particles may be important during some of the days. A better correlation is observed when comparing lidar and model results because most of the anthropogenic haze effect is removed. Figure 11 presents a selection of vertical profiles of the extinction coefficient at both wavelengths from the lidar above 1-km height and the model experiments. Lidar data were averaged around model height levels. Maximum extinction (backscatter) coefficients reached $\sim 70 \mathrm{Mm}^{-1}\left(\sim 1.2 \mathrm{Mm}^{-1} \mathrm{sr}^{-1}\right)$ at $1064 \mathrm{~nm}$ and $80 \mathrm{Mm}^{-1}\left(\sim 1.4 \mathrm{Mm}^{-1} \mathrm{sr}^{-1}\right)$ at $532 \mathrm{~nm}$. The agreement between lidar and model results are excellent when keeping in mind that lidar ratio uncertainties are always of the order of $20-30 \%$ or about 20 sr [Mattis et al., 2002]. It is remarkable that M4 exhibits a general tendency to deliver more dust in the lowest levels (higher surface concentration) while G8 delivers more dust in the upper levels. This is related to particle size distribution and its influence on gravitational settling. However, the scope of this study is not to evaluate surface concentration which should be performed against regional background air quality stations with weak influence of anthropogenic pollution.

\section{Summary and Conclusions}

[38] The western Mediterranean is affected by Saharan dust events mostly in spring and summer. In June 2002 a long event was followed by a EARLINET lidar device in Barcelona and two AERONET Sun photometers located at AR (Spain) and AV (France). The spatial and temporal evolution, optical properties and vertical structure of the dust plume were analyzed in detail together with DREAM dust modeling experiments. The main results and conclusions are summarized as follows:

[39] 1. Sequences of 3 main meteorological low index circulation patterns (high pressure over the western Mediterranean, high pressure over northwestern Africa and low pressure over southwestern Portugal) explained the persistence of dust over the region for more than 2 weeks. Dust was present mainly between $1-$ and $5-\mathrm{km}$ height affecting most parts of the IP and reaching western/central Europe.

[40] 2. The Sun photometer AOD raised up to $0.35(0.28)$ at $532(1064) \mathrm{nm}$ and the $\mathrm{AE}$ oscillated between 0.3 and 1.3 at AR while they reached $0.45(0.29)$ with the $\mathrm{AE}$ oscillating between 0.5 and 2.3 at Avignon, indicating the higher influence of fine anthropogenic aerosols at the latter station. However, the single-scattering albedo showed higher absorption at El Arenosillo than at Avignon.

[41] 3. The dust horizontal and vertical structure simulated by DREAM showed very good qualitative agreement when compared to SeaWIFS satellite images and lidar height-time displays over Barcelona.

[42] 4. A more detailed bin method and two different dust source distributions (G8 and D8) were implemented into the DREAM model and compared to the current operational configuration (M4). All three model parameterizations showed a general tendency toward underprediction of the AOD when compared to Sun photometer for increasing AE values because of the influence of fine anthropogenic particles which are not considered in our modeling system. This is clearly visible over AV at $532 \mathrm{~nm}$. G8 shows the best AOD peak predictions under major influence of the dust plume while M4 yields the worst peak predictions. The assumption of a constant specific cross section for M4 seems to be too coarse and outlines the limitations of a 

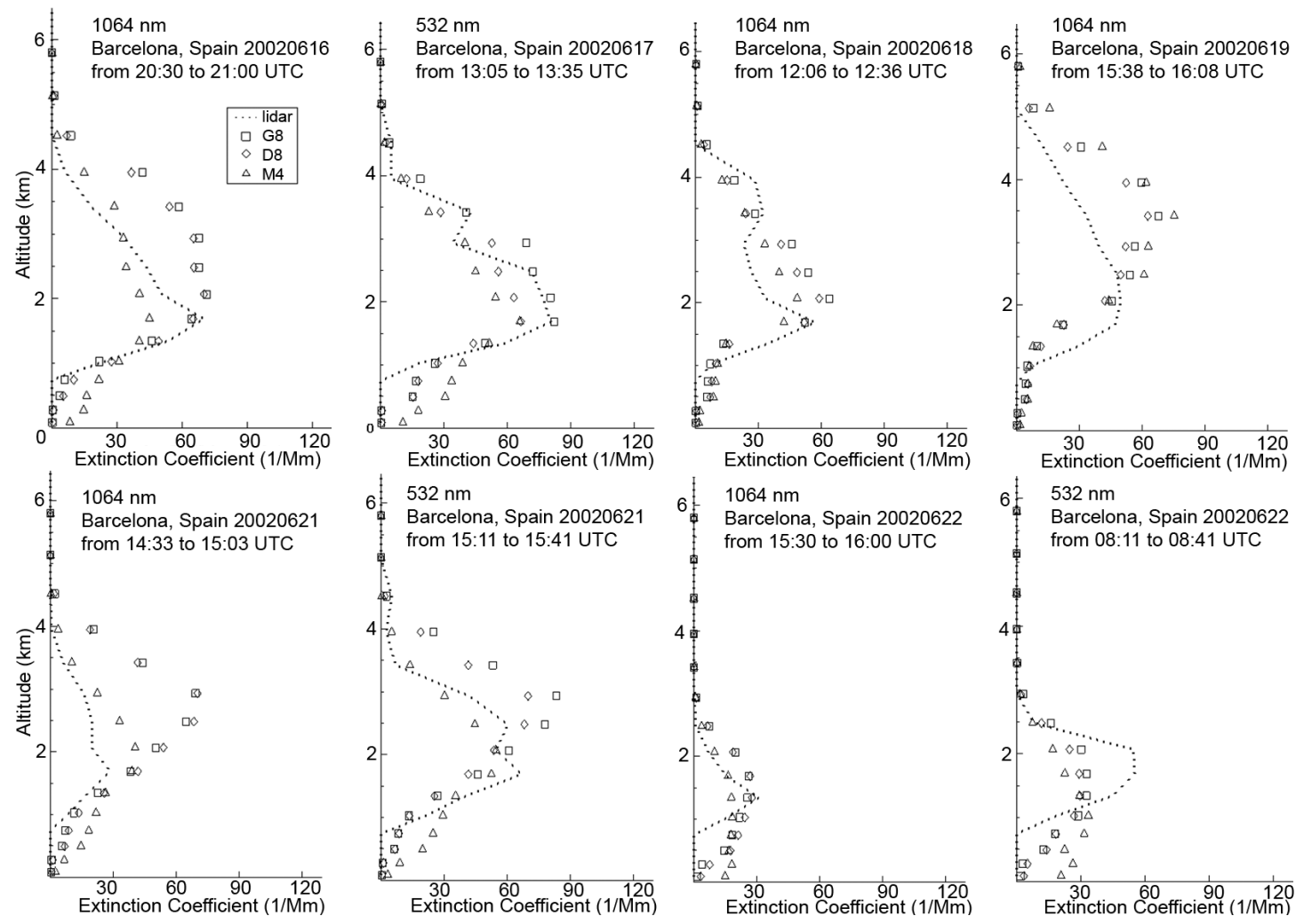

Figure 11. Comparisons of modeled and observed vertical profiles of the extinction coefficient over Barcelona for M4, G8, and D8.

nondetailed bin method when evaluating the model products against optical data. However, because of the influence of fine anthropogenic particles, the conclusions concerning the performance of G8 and D8 are limited. This could be partly solved with the use of a multiwavelength Raman lidars.

[43] 5. When Sun photometers record AE values larger than $0.6-0.8$, the discrepancies between modeled and observed AOD are significant. This is a clear sign for the fact that anthropogenic aerosols contribute significantly to the observed aerosol optical properties. Thus the model can help to separate the dust from the anthropogenic effect in the measurements. In this context, the anticorrelation of the observed $\mathrm{AE}$ and the modeled AOD can be a good indicator for operational dust model evaluation with Sun photometers and AE threshold values can be used as a discard procedure of anthropogenically polluted measurements.

[44] 6. A constant lidar ratio of $60 \mathrm{sr}$ was assumed to invert the lidar profiles over Barcelona. The modeled profiles from the 3 parameterizations are in very good agreement with observations with a tendency toward overprediction in the upper levels of the dust plume. The uncertainties that are present in elastic lidar inversions $(20-30 \%)$ are of the same order of magnitude than the differences between the model experiments. Again, Raman lidars seem to be the best alternative to address these aspects by accurately determining the extinction coefficient.

[45] 7. In addition to their ability to assess dust structure and optical properties with high vertical resolution, lidars should play a major role in future operational dust model validation and assimilation activities if observations are performed in regular time intervals and with reasonably good density and distribution of stations in the horizontal located over a particular region. There are several recent attempts to establish lidar networks and to provide regular aerosol profiling: EARLINET in Europe [Bösenberg et al., 2003] and AdNet in the far east [Murayama et al., 2001]. Namely, lidar data should be used for model initialization in a similar way as the radiosounding data on temperature, wind and humidity vertical profiles are used in the operational weather data assimilation systems.

[46] Acknowledgments. This work was developed with Spanish Ministry of Science and Technology and FEDER funds under the research contract REN2003-09753-C02. This work was also partly funded by National Aeronautics and Space Administration (NASA) under the Project "Public Health Applications in Remote Sensing (PHAiRS)" and by the European Union Project "Atmospheric Deposition and Impact of Pollutants, Key Elements and Nutrients on the Open Mediterranean Sea (ADIOS)." ESA and MCYT are thanked respectively for the external postdoctoral fellowship and the Ramón y Cajal position held by M. Sicard. The authors gratefully acknowledge the NOAA Air Resources Laboratory (ARL) for the provision of READY website (http://www.arl.noaa.gov/ ready.html), the SeaWIFS-NASA project and Gilbert Sappe and Luc Blarel for proving Avignon AERONET data. The National Institute for Aerospace Technology (INTA) of Spain is thanked for providing El Arenosillo AERONET data.

\section{References}

Alpert, P., and E. Ganor (2001), Sahara mineral dust measurements from TOMS: Comparison to surface observations over the Middle East for the extreme dust storm, 14-17 March 1998, J. Geophys. Res., 106, 18,27518,286 .

Ansmann, A., et al. (2003), Long-range transport of Saharan dust to northern Europe: The $11-16$ October 2001 outbreak observed with EARLINET, J. Geophys. Res., 108(D24), 4783, doi:10.1029/2003JD003757. 
Avila, A., I. Queralt-Mitjans, and M. Alarcón (1997), Mineralogical composition of African dust delivered by red rains over northeastern Spain, J. Geophys. Res., 102, 21,977-21,996.

Balis, D. S., C. S. Zerefos, K. Kourtidis, A. F. Bais, A. Hofzumahaus, A. Kraus, R. Schmitt, M. Blumthaler, and G. P. Gobbi (2002), Measurements and modeling of the photolysis rates during the Photochemical Activity and Ultraviolet Radiation (PAUR) II campaign, J. Geophys. Res., 107(D18), 8138, doi:10.1029/2000JD000136.

Balis, D. S., V. Amiridis, S. Nickovic, A. Papayannis, and C. Zerefos (2004), Optical properties of Saharan dust layers as detected by a Raman lidar at Thessaloniki, Greece, Geophys. Res. Lett., 31, L13104, doi:10.1029/2004GL019881.

Bergametti, G., L. Gomes, G. Coude-Gaussen, P. Rognon, and M. N. Le Coustumer (1989), African dust observed over Canary Islands: Source regions, identification and transport pattern for some summer situation, J. Geophys. Res., 94, 14,855-14,864.

Böckmann, C., et al. (2004), Aerosol Lidar Intercomparison in the framework of the EARLINET project. 2. Aerosol backscatter algorithms, Appl. Opt., 43, 977-989.

Bösenberg, J., et al. (2003), EARLINET: A European Aerosol Research Lidar Network, Rep. 348, MPI-Rep. 337, 191 pp., Max-Planck-Inst. für Meteorol., Hamburg, Germany.

Chin, M., P. Ginoux, S. Kinne, O. Torres, B. N. Holben, B. N. Duncan, R. V. Martin, J. A. Logan, A. Higurashi, and T. Nakajima (2002), Tropospheric aerosol optical thickness from the GOCART model and comparisons with satellite and Sun photometer measurements, J. Atmos. Sci., 59, 461-483.

D'Almeida, D. A. (1987), On the variability of desert aerosol radiative characteristics, J. Geophys. Res., 92, 3017-3026.

Dentener, F. J., G. R. Carmichael, Y. Zhang, J. Lelieveld, and P. J. Crutzen (1996), Role of mineral aerosol as a reactive surface in the global troposphere, J. Geophys. Res., 101(D17), 22,869-22,890.

Di Sarra, A., T. Di Iorio, M. Cacciani, G. Fiocco, and D. Fuà (2001), Saharan dust profiles measured by lidar at Lampedusa, J. Geophys. Res., 106(D10), 10,335-10,348.

Dubovik, O., and M. D. King (2000), A flexible inversion algorithm for retrieval of aerosol optical properties from Sun and sky radiance measurements, J. Geophys. Res., 105, 20,673-20,696.

Dubovik, O., A. Smirnov, B. N. Holben, M. D. King, Y. J. Kaufman, T. F. Eck, and I. Slutsker (2000), Accuracy assessments of aerosol optical properties retrieved from Aerosol Robotic Network (AERONET) Sun and sky radiance measurements, J. Geophys. Res., 105, 9791-9806.

Dubovik, O., B. Holben, T. F. Eck, A. Smirnov, Y. J. Kaufman, M. D. King, D. Tanré, and I. Slutsker (2002a), Variability of absorption and optical properties of key aerosol types observed in worldwide locations, J. Atmos. Sci., 59, 590-608.

Dubovik, O., B. N. Holben, T. Lapyonok, A. Sinyuk, M. I. Mishchenko, P. Yang, and I. Slutsker (2002b), Non-spherical aerosol retrieval method employing light scattering by spheroids, Geophys. Res. Lett., 29(10), 1415, doi:10.1029/2001GL014506.

Dulac, F., D. Tanré, G. Bergametti, P. Buat-Ménard, M. Desbois, and D. Sutton (1992a), Assessment of the African airborne dust mass over the western Mediterranean sea using Meteosat data, J. Geophys. Res., 97, 2489-2506.

Dulac, F., D. Bergametti, R. Losno, E. Remoudaki, L. Gomes, U. Ezat, and P. Buat-Ménard (1992b), Dry deposition of mineral aerosol particles in the atmosphere: Significance of the large size fraction, in Precipitation Scavenging and Atmosphere-Surface Exchange, vol. 2, edited by S. E. Schwartz and W. G. N. Slinn, pp. 841-854, Taylor and Francis, Philadelphia, Pa.

Fernald, F. G. (1984), Analysis of atmospheric lidar observations: Some comments, Appl. Opt., 23, 652-653.

Fouquart, Y., B. Bonnel, G. Brogniez, J. C. Buriez, L. Smith, and J. J. Morcrette (1987), Observations of Saharan aerosols: Results of ECLATS field experiment, part II, Broadband radiative characteristics of aerosols and vertical flux divergence, J. Clim. Appl. Meteorol., 26, 38-52.

Gobbi, G. P., F. Barnaba, R. Giorgi, and A. Santacasa (2000), Altituderesolved properties of a Saharan dust event over the Mediterranean, Atmos. Environ., 34, 5119-5127.

Gomes, L., G. Bergametti, G. Coudé-Gaussen, and P. Rognon (1990), Submicron desert dusts: A sandblasting process, J. Geophys. Res., 95, $13,927-13,935$.

Guerzoni, S., W. Landuzzi, R. Lenaz, G. Quarantotto, G. Cesar, G. Rampazzo, and E. Molinaroli (1992), Mineral atmospheric particulate from South to NW Mediterranean: Seasonal variations and characteristics, Water. Pollut. Res. Rep., 28, 483-493.

Hamonou, E., P. Chazette, D. Balis, F. Dulac, X. Schneider, E. Galani, G. Ancellet, and A. Papayannis (1999), Characterization of the vertical structure of Saharan dust export to the Mediterranean basin, J. Geophys. Res., 104(D18), 22,257-22,270.
Hess, M., P. Koepke, and I. Schult (1998), Optical properties of aerosols and clouds: The software package OPAC, Bull. Am. Meteorol. Soc., 79, $831-844$

Holben, B. N., et al. (1998), AERONET-A federated instrument network and data archive for aerosol characterization, Remote Sens. Environ., 66, $1-16$.

Israelevich, P. L., Z. Levin, J. H. Joseph, and E. Ganor (2002), Desert aerosol transport in the Mediterranean region as inferred from the TOMS aerosol index, J. Geophys. Res., 107(D21), 4572, doi:10.1029/ 2001JD002011.

Israelevich, P. L., E. Ganor, Z. Levin, and J. H. Joseph (2003), Annual variations of physical properties of desert dust over Israel, J. Geophys. Res., 108(D13), 4381, doi:10.1029/2002JD003163.

Kallos, G., et al. (1997), The regional weather forecasting system SKIRON: An overview, in Proceedings of the Symposium on Regional Weather Prediction on Parallel Computer Environments, edited by G. Kallos, V. Kotroni, and K. Lagouvardos, pp. 109-122, Univ. of Athens, Athens, Greece.

Kaufman, Y. J., D. Tanré, O. Dubovik, A. Karnieli, and L. A. Remer (2001), Absorption of sunlight by dust as inferred from satellite and ground-based remote sensing, Geophys. Res. Lett., 28, 1479-1482.

Klett, J. D. (1981), Stable analytical inversion solution for processing lidar returns, Appl. Opt., 20, 211-220.

Koepke, P., and M. Hess (1988), Scattering functions of tropospheric aerosols: The effect of nonspherical particles, Appl. Opt., 27, 2422-2430.

Koepke, P., M. Hess, I. Schult, and E. P. Shettle (1997), Global aerosol data set, report, Max-Planck-Inst. für Meteorol., Hamburg, Germany.

Kremling, K., and P. Streau (1993), Saharan dust influenced trace element fluxes in deep North Atlantic subtropical waters, Deep Sea Res., Part I, $40,1155-1168$.

Levin, Z., E. Ganor, and V. Gladstein (1996), The effects of desert particles with sulfate on rain formation in the eastern Mediterranean, J. Appl. Meteorol., 35, 1511-1523.

Li, X., H. Maring, D. Savoie, K. Voss, and J. M. Prospero (1996), Dominance of mineral dust in aerosol light scattering in the North Atlantic trade winds, Nature, 380, 416-419.

Loye-Pilot, M. D., and J. M. Martin (1996), Saharan dust input to the western Mediterranean: An eleven years record in Corsica, in The Impact of Desert Dust Across the Mediterranean, edited by S. Guerzoni and R. Chester, pp. 191-200, Springer, New York.

Maring, H., D. L. Savoie, M. A. Izaguirre, L. Custals, and J. S. Reid (2003), Mineral dust aerosol size distribution change during atmospheric transport, J. Geophys. Res., 108(D19), 8592, doi:10.1029/2002JD002536.

Matthias, V., et al. (2004), Aerosol lidar intercomparison in the framework of EARLINET project. 1. Instruments, Appl. Opt., 43, 961-976.

Mattis, I., A. Ansmann, D. Müller, U. Wandinger, and D. Althausen (2002), Dual wavelength Raman lidar observations of the extinction-to-backscatter ratio of Saharan dust, Geophys. Res. Lett., 29(9), 1306, doi:10.1029/ 2002GL014721.

Mishchenko, M. I., L. D. Travis, R. A. Kahn, and R. A. West (1997), Modeling phase functions for dustlike tropospheric aerosols using a shape mixture of randomly oriented polydisperse spheroids, J. Geophys. Res., 102, 16,831-16,847.

Mishchenko, M. I., J. W. Hovenier, and L. D. Travis (2000), Light Scattering by Nonspherical Particles, 690 pp., Elsevier, New York.

Moulin, C., F. Dulac, C. E. Lambert, P. Chazette, I. Jankowiak, B. Chatenet, and F. Lavenu (1997), Long term daily monitoring of Saharan dust load over ocean using Meteosat ISCCP-B2 data: 2. Accuracy of the data and validation using sunphotometer measurements, J. Geophys. Res., 102, 16,959-19,969.

Moulin, C., et al. (1998), Satellite climatology of African dust transport in the Mediterranean atmosphere, J. Geophys. Res., 103, 13,13713,144 .

Müller, D., I. Mattis, U. Wandinger, D. Althausen, A. Ansmann, O. Dubovik, S. Eckhardt, and A. Stohl (2003), Saharan dust over a central European EARLINET-AERONET site: Combined observations with Raman lidar and Sun photometer, J. Geophys. Res., 108(D12), 4345, doi:10.1029/2002JD002918

Murayama, T., et al. (2001), Ground-based network observation of Asian dust events of April 1998 in east Asia, J. Geophys. Res., 106(D16), $18,345-18,359$

Nickovic, S., and S. Dobricic (1996), A model for long-range transport of desert dust, Mon. Weather Rev, 124, 2537-2544.

Nickovic, S., A. Papadopoulos, O. Kakaliagou, and G. Kallos (2001), Model for prediction of desert dust cycle in the atmosphere, J. Geophys. Res., 106, 18,113-18,129.

Nickovic, S., G. Pejanovic, E. Ozsoy, C. Pérez, and J. M. Baldasano (2004), Interactive radiation-dust model: A step to further improve weather forecasts, paper presented at International Symposium on Sand and Dust Storm, World Meteorol. Organ., Beijing, China, 12-14 Sept. 
N'Tchayi, M. G., J. J. Bertrand, and S. E. Nicholson (1997), The diurnal and seasonal cycles of wind-borne dust over Africa north of the equator, J. Appl. Meteorol., 36, 868-882.

Özsoy, E., N. Kubilay, S. Nickovic, and C. Moulin (2001), A hemispheric dust storm affecting the Atlantic and Mediterranean (April 1994): Analyses, modelling, ground-based measurements and satellite observations, J. Geophys. Res., 106, 18,439-18,460.

Papayannis, A., D. Balis, V. Amiridis, G. Chourdakis, G. Tsaknakis, C. Zerefos, A. D. A. Castanho, S. Nickovic, S. Kazadzis, and J. Grabowski (2005), Measurements of Saharan dust aerosols over the eastern Mediterranean using elastic backscatter-Raman lidar, spectrophotometric and satellite observations in the frame of the EARLINET project, Atmos. Chem. Phys., 5(8), 2065-2079.

Pérez, C., M. Sicard, O. Jorba, A. Comerón, and J. M. Baldasano (2004), Summertime re-circulations of air pollutants over the north-eastern Iberian coast observed from systematic EARLINET lidar measurements in Barcelona, Atmos. Environ., 38, 3983-4000.

Pérez, C., S. Nickovic, G. Pejanovic, J. M. Baldasano, and E. Özsoy (2006), Interactive dust-radiation modeling: A step to improve weather forecasts, J. Geophys. Res., doi:10.1029/2005JD006717, in press.

Prospero, J. M., R. A. Glaccum, and R. T. Nees (1981), Atmospheric transport of soil dust from Africa to South America, Nature, 289 $570-572$.

Reichholf, J. H. (1986), Is Saharan dust a major source of nutrients for the Amazonian forest, Suud. Neotrop. Fauna Environ., 21, 251-255.

Rocadenbosch, F., C. Soriano, A. Comerón, J. M. Baldasano, A. Rodríguez, C. Muñoz, and D. García-Vizcaíno (2000), 3D scanning portable backscatter lidar platform for atmospheric remote sensing: Performance and architecture overview, Proc. SPIE Int. Soc. Opt. Eng., 4168, 158-169.

Rodríguez, S., X. Querol, A. Alastuey, G. Kallos, and O. Kakaliagou (2001), Saharan dust contribution to PM10 and TSP levels in Southern and Eastern Spain, Atmos. Environ., 35(14), 2433-2447.

Sasano, Y., and H. Nakane (1984), Significance of the extinction/backscatter ratio and the boundary value term in the solution for the two-component lidar equation, Appl. Opt., 23, 11-12.

Sasano, Y., E. V. Browell, and S. Ismail (1985), Error caused by using a constant extinction/backscattering ratio in the lidar solution, Appl. Opt. 24, 3929-3932.

Schulz, M., Y. J. Balkanski, W. Guelle, and F. Dulac (1998), Role of aerosol size distribution and source location in a three-dimensional simulation of a Saharan dust episode tested against satellite-derived optical thickness, J. Geophys. Res., 103, 10,579-10,592.

Schütz, L. (1980), Long range transport of desert dust with special emphasis on the Sahara, Ann. N. Y. Acad. Sci., 338, 515-532.

Schütz, L., R. Jaenicke, and H. Petrick (1981), Saharan dust transport over the North Atlantic Ocean, in Desert Dust: Origin, Characteristics and
Effect on Man, edited by T. L. Péwé, pp. 87-100, Geol. Soc. of Am., Boulder, Colo.

Shettle, E. P. (1984), Optical and radiative properties of a desert aerosol model, in Proceedings of the Symposium on Radiation in the Atmosphere, edited by G. Fiocco, pp. 74-77, A. Deepak, Hampton, Va.

Shettle, E. P., and R. W. Fenn (1979), Models for the aerosols of the lower atmosphere and the effects of humidity variations on their optical properties, Environ. Res. Pap., AFGL-TR-79-214, Air Force Geophys. Lab., Hanscom Air Force Base, Mass.

Sokolik, I. N., D. M. Winker, G. Bergametti, D. A. Gillette, G. Carmichael, Y. J. Kaufman, L. Gomes, L. Schuetz, and J. E. Penner (2001), Introduction to special section: Outstanding problems in quantifying the radiative impacts of mineral dust, J. Geophys. Res., 106, 18,015-18,027.

Tegen, I., and I. Fung (1994), Modeling of mineral dust in the atmosphere: Sources, transport and optical thickness, J. Geophys. Res., 99, 22,89722,914 .

Tegen, I., and A. A. Lacis (1996), Modeling of particle size distribution and its influence on the radiative properties of mineral dust aerosol, J. Geophys. Res., 101, 19,237-19,244.

Yin, D., S. Nickovic, B. Barbaris, B. Chandy, and W. A. Sprigg (2005), Modeling wind-blown desert dust in the southwestern United States for public health warning: A case study, Atmos. Environ., 39(33), 62436254

Yin, Y., S. Wurzler, Z. Levin, and T. G. Reisin (2002), Interactions of mineral dust particles and clouds: Effects on precipitation and cloud optical properties, J. Geophys. Res., 107(D23), 4724, doi:10.1029/ 2001JD001544.

Zender, C. S., H. Bian, and D. Newman (2003), Mineral Dust Entrainment and Deposition (DEAD) model: Description and 1990s dust climatology, J. Geophys. Res., 108(D14), 4416, doi:10.1029/2002JD002775.

Zerefos, C. S., et al. (2002), Photochemical Activity and Solar Ultraviolet Radiation Modulation Factors (PAUR): An overview of the project, J. Geophys. Res., 107(D18), 8134, doi:10.1029/2000JD000134.

J. M. Baldasano and C. Pérez, Earth Sciences Division, Barcelona Supercomputing Center, E-08034 Barcelona, Spain. (carlos.perez@) bsc.es)

V. E. Cachorro, Atmospheric Optic Group, Universidad de Valladolid, E-47071 Valladolid, Spain.

S. Nickovic, Atmospheric Research and Environment Program, Environment Division, World Meteorological Organization, CH-1211 Geneva, Switzerland.

F. Rocadenbosch and M. Sicard, Remote Sensing Laboratory, Group of Electromagnetic Engineering and Photonics, Department of Signal Theory and Communications, Universitat Politècnica de Catalunya, E-08034 Barcelona, Spain. 